\title{
Numbers and Proportions of GABA-Immunoreactive Neurons in Different Areas of Monkey Cerebral Cortex
}

\author{
S. H. C. Hendry, H. D. Schwark, E. G. Jones, and J. Yan \\ Department of Anatomy and Neurobiology, University of California, Irvine, California 92717
}

The number and proportion of neurons displaying GABA immunoreactivity were determined for $50-\mu \mathrm{m}$-wide columns through the thickness of 10 areas of monkey cerebral cortex, including the precentral motor area (area 4), 3 cytoarchitectonic fields of the first somatic sensory area (areas $3 b, 1$, and 2), 2 areas of parietal association cortex (areas 5 and 7 ), the first and second visual areas (areas 17 and 18), area 21 of the temporal lobe, and areas of the orbital and lateral frontal cortex. Methods of fixation and immunocytochemical processing were designed to maximize the number of stained cells in 15- $\mu \mathrm{m}$-thick frozen sections and $1-\mu \mathrm{m}$-thick plastic sections. In 8 of the 10 areas the number and proportion of GABA-immunoreactive neurons per $50-\mu \mathrm{m}$-wide column were found to be the same (34-43 cells/column; $25 \%$ of the total neuronal population). Areas 17 and $3 \mathrm{~b}$ differed. Area 17 contained $50 \%$ more GABA-immunoreactive neurons (5266 cells/column) but more than twice the total number of neurons, so that the GABA cells made up less than $20 \%$ of the total. In 3 monkeys, the number and proportion of GABApositive neurons per $50-\mu \mathrm{m}$-wide column in area $3 \mathrm{~b}$ were smaller than in adjacent areas of sensorimotor cortex (2642 cells/column; 19-22\%). In 2 other monkeys, the number and proportion (34-43 cells/column; 24-26\%) were the same as in adjacent areas.

Despite the similarity among most areas of monkey cortex, within some areas, the number of GABA-positive neurons per $50-\mu \mathrm{m}$-wide column varied as much as $30 \%$. These variations form a significant, repeating pattern only in area 18, where narrow bands (150-200 $\mu \mathrm{m}$ wide) of relatively few stained cells alternated with either narrow or wide bands (600-700 $\mu \mathrm{m}$ wide) in which columns contained more cells.

The GABA-immunoreactive neurons were unevenly distributed across layers, with every area containing large numbers and proportions of stained cells in layer II, and every area but area 4 displaying a second concentration in the principal thalamocortical recipient layers. In area 4, the number of GABA-positive neurons declined sharply from layer II to layer III and remained low through layer VI. For areas displaying the greatest intra-areal variability, only 1 or 2 layers contributed significantly to that variability (layer IV in area $3 b$, layers III and V in area 18, and layers II and III in area 17).

\footnotetext{
Received Aug. 26, 1986; revised Nov. 24, 1986; accepted Nov, 25, 1986.

Supported by Grants EY 06432, NS 21377, and NS 07650 from the National Institutes of Health, United States Public Health Service. S.H.C.H. is a Fellow of the Alfred P. Sloan Foundation.

Correspondence should be addressed to Stewart Hendry at the above address.

Copyright (c) 1987 Society for Neuroscience $0270-6474 / 87 / 051503-17 \$ 02.00 / 0$
}

The distribution of GABA-immunoreactive neurons was also examined in tangential sections through area 17 by staining sections cut parallel to the flattened opercular surface of the occipital lobe. The GABA staining in every other section through layers II and III was compared with the staining for cytochrome oxidase $(\mathrm{CO})$ in the adjacent sections. Although variations in GABA cell densities were found within a single section, no correlations were found between GABA and $\mathrm{CO}$ staining since high and low densities were found both in $\mathrm{CO}$ patches and in the spaces between them.

These data indicate that (1) when the number and proportion of GABA neurons are considered, many areas of the monkey cerebral cortex appear to be homogeneous; (2) the principal difference among areas - namely, the laminar distribution of GABA neurons-may be related to the varied positions of thalamocortical afferent terminations in these areas; and (3) real variations in GABA cell distributions exist within individual areas, but their significance is currently unclear.

Many neurons in the mammalian cerebral cortex appear to use GABA as a neurotransmitter. Both GABA and its synthesizing enzyme, glutamic acid decarboxylase (GAD) are present in relatively high concentrations in the cortex (Hirsch and Robins, 1962). GABA is released upon activation of cortical neurons (Iversen et al., 1971), and when, applied iontophoretically, it mimics the actions of stimulus-induced inhibition (Krnjević and Schwartz, 1967; Krnjevic, 1974, 1984). When these inhibitory effects of GABA are blocked by the competitive antagonist bicuculline, the size of the receptive fields of certain populations of somatosensory cortical neurons increases (Hicks and Dykes, 1983; Dykes et al., 1984) and the selectivity of responses of many visual cortical neurons for the orientation, length and direction of movement of a visual stimulus is abolished or reduced (Sillito, 1984). Experimental focal epilepsy is associated with the loss of cortical GABA neurons, apparently through a loss of their inhibitory influences (Ribak et al., 1979, 1986). These data suggest that many activities critical to the normal functioning of the cerebral cortex occur at synapses formed by GABA neurons.

The cortical GABA neurons are a heterogeneous group of cells, displaying marked variability in morphology (Freund et al., 1983; Houser et al., 1984; DeFelipe et al., 1986) and immunoreactivity for substances other than GABA and GAD (Hendry et al., 1984a; Schmechel et al., 1984; Somogyi et al., 1984; Celio, 1986). However, despite detailed knowledge of the form, organization, and distribution of the cortical GABA cells, data concerning the size of the cortical cell population that they make up are limited. 
Previous quantitative studies of cortical cells have focuscd primarily on estimating the density of all neurons present in various areas and species (Rockel et al., 1980; O'Kusky and Colonnier, 1982). Studies by Powell and his colleagues (Powell, 1981) suggest that a basic uniformity exists among cortical areas of several mammalian species, in that the same number of neurons occupy narrow ( $30-\mu \mathrm{m}$-wide) cortical columns in each cortical area of several mammalian species, except in the primary visual area (area 17) of primates, where at least twice the number of neurons per column is found. This strict numerical uniformity has been questioned (Peters and Kara, 1985), and studies of the distribution of histochemically and immunocytochemically stained neurons and processes (Graybiel and Ragsdale, 1982; Hendry et al., 1984b; Lewis et al., 1987) and autoradiographically localized receptor sites (Wise and Herkenham, 1982) suggest a great degree of heterogeneity from area to area. In the present study we have examined several areas of cerebral cortex from Old World monkeys for the number and density of GABA neurons. Our data indicate that, with the exception of area 17 and possibly area $3 \mathrm{~b}$, cortical areas are homogeneous with respect to the mean number and proportion of GABA-immunoreactive neurons they contain, albeit with some variability in most areas.

\section{Materials and Methods}

\section{Tissue preparation}

Six normal cynomolgus monkeys (Macaca fascicularis) weighing 2.75 $4 \mathrm{~kg}$ were used in this study. All were deeply anesthetized with Nembutal and perfused through the heart with mixtures of paraformaldehyde and glutaraldehyde in $0.1 \mathrm{~m}$ phosphate buffer $(\mathrm{pH}=7.4)$. Two were perfused with $2 \%$ paraformaldchyde and $0.1 \%$ glutaraldehyde (CM 181, CM 183), 2 with $2 \%$ paraformaldehyde and $0.2 \%$ glutaraldehyde (CM $184, \mathrm{CM}$ $189)$, and 1 with $2 \%$ paraformaldehyde and $0.4 \%$ glutaraldehyde (CM 187). The sixth monkey was perfused with $1 \%$ paraformaldehyde and $2.5 \%$ glutaraldehyde. The brains were removed and cut into $1-\mathrm{cm}$-thick blocks, which were postfixed in the perfusate at $4^{\circ} \mathrm{C}$ for 4 or $6 \mathrm{hr}$. Sagittally oriented blocks were taken from the pre- and postcentral gyri, the superior and inferior parietal lobules, and the occipital lobe. Blocks cut in the frontal plane were taken from the temporal lobe and the frontal lobe. When removed from the fixative, the blocks were placed in either 7 or $30 \%$ sucrose in $0.1 \mathrm{M}$ phosphate buffer. Blocks placed in $7 \%$ sucrose were stored at $4^{\circ} \mathrm{C}$ overnight and cut at $30 \mu \mathrm{m}$ on a Vibratome. Blocks placed in $30 \%$ sucrose were stored at $4^{\circ} \mathrm{C}$ until they had sunk and were then rapidly frozen and cut at 10,15 , or $30 \mu \mathrm{m}$. All sections were collected in icc-cold $0.1 \mathrm{M}$ phosphate buffer.

Blocks from the occipital lobe were flattened between weighted slides while in $30 \%$ sucrose and later cut parallel to the opercular surface. Alternating 15 and $30 \mu \mathrm{m}$ sections were cut, the thinner to be processed for immunocytochemistry (see below) and the thicker for the histochemical localization of cytochrome oxidase (CO) (Wong-Riley, 1979).

\section{Immunocytochemical staining}

Selected sections, $1-1.5 \mathrm{~cm}$ long, were preincubated in 5\% normal swine serum (NSS) or $5 \%$ normal goat serum (NGS) and $0.3 \%$ Triton X-100 in $0.1 \mathrm{M}$ phosphate huffer at $4^{\circ} \mathrm{C}$ for $2 \mathrm{hr}$. They were transferred to the same solution to which rabbit anti-GABA antiserum (Immuno Nuclear, Inc.) diluted 1:1500 or 1:3000 had been added, and they were incubated for $24 \mathrm{hr}$ at $4^{\circ} \mathrm{C}$. After extensive washing $\left(1 \mathrm{hr}\right.$ at $4^{\circ} \mathrm{C}, 1 \mathrm{hr}$ at room temperature) in $0.1 \mathrm{M}$ phosphate buffer, the sections were incubated in a 1:100 solution of either unlabeled swine anti-rabbit immunoglobulins (Dako, Inc.) or biotinylated goat anti-rabbit immunoglobulins (Vector Labs) for $1 \mathrm{hr}$ (frozen sections) or $2.5 \mathrm{hr}$ (Vibratome sections) at room temperature. The sections were washed for $30 \mathrm{~min}$ in several changes of phosphate buffer and incubated at room temperature in rabbit peroxidase-antiperoxidase (PAP) complex, diluted $1: 100$, or in avidinbiotin-peroxidase complex (Vector Labs) for $1.5 \mathrm{hr}$ (frozen sections) or $4 \mathrm{hr}$ (Vibratome sections). They were washed in several changes of phosphate buffer and reacted in 3,3'-diaminobenzidine (DAB) tetra- hydrochloridc according to LaVail and LaVail (1974). Incubations in $\mathrm{DAB}$ were allowed to proceed for 5-7 min before sections were transferred to phosphate buffer. The sections were then mounted onto gelatinsubbed slides, dehydrated in ethanol, cleared in xylene, and coverslipped with DPX. Adjacent sections were incubated in the same solutions but without the immunocytochemical reagents. They were mounted, lipids were extracted in chloroform, and the sections were stained with thionin. Additional sections from the same blocks were incubated in anti-GABA that had been preadsorbed with an excess $(15,30$, or $45 \mu \mathrm{g} / \mathrm{ml})$ of GABA, glutamate, aspartate, glycine, taurine, cholecystokinin octapeptide, somatostatin, neuropeptide $Y$, or substance P. Preadsorption in GABA at these concentrations reduced staining to an extremely light, diffuse haze. No changes in staining were seen following preincubations in the other substances.

These incubation conditions were used after numerous tests were made of section thickness, antisera dilutions, detergent, and normal sera concentrations and time of incubations. Certain changes, such as the concentration of normal serum $(1-10 \%)$ and the duration of the DAB reaction were found to produce no change in the numbers of stained neurons. However, other conditions, such as section thickness and detergent concentration, greatly affected the numbers of cells stained (see Results).

Selected sections from each area of cortex, cut on a Vibratome and stained immunocytochemically for GABA, were postfixed in $1 \%$ osmium tetroxide in $0.1 \mathrm{M}$ phosphate buffer for $30 \mathrm{~min}$, washed in buffer, and dehydrated in ethanol. They were infiltrated with Spurr's resin and embedded flat between a silicon-coated slide and a weighted, siliconcoated coverslip. After they had hardened overnight at $60^{\circ} \mathrm{C}$, the sections were examined and regions containing the greatest density of stained cells were cut into small pieces with iridectomy scissors and mounted with acrylic glue onto a blank cast from Spurr's resin. They were trimmed and resectioned at $1 \mu \mathrm{m}$, heat mounted onto clean glass slides, and counterstained with methylene blue and Azur II (Richardson et al., 1960).

\section{Data collection}

Numbers. The numbers of GABA-immunoreactive neurons were determined for $50-\mu \mathrm{m}$-wide columns that spanned all layers of cortex and included the white matter to a depth of $200 \mu \mathrm{m}$ subjacent to layer VI. Three methods were used to determine GABA cell numbers: (1) Photomicrographic montages through each area were made at a final magnification of 480 . Lines were drawn on the montages, marking out a rectangle $500 \mu \mathrm{m}$ wide and extending through the thickness of the cortex and into the white matter; all the GABA-positive cells within the lines were counted with a Zeiss Zidas digitizing tablet. The number of cells per $50-\mu \mathrm{m}$-wide column was then derived by dividing by 10 ; this value was less likely to vary with minor changes in the tissue (e.g., the presence of blood vessels) than in counts of individual $50-\mu \mathrm{m}$-wide columns. (2) Photographic montages were made at a final magnification of 960 . Lines were drawn on the montage, dividing it into five $50-\mu \mathrm{m}$-wide columns through the thickness of the cortex, and the number of GABA cells in each column was counted on the Zidas tablet. (3) GABA-positive cells were counted directly from the slide by using a camera lucida to project into the microscope a drawing of a rectangle calibrated to cover an area $50 \times 200 \mu \mathrm{m}$ at the magnification used $(\times 1250)$. The cells lying within the borders of this $50-\mu \mathrm{m}$-wide column were then counted. Selected single columns were counted or, in many instances, a series of contiguous $50-\mu \mathrm{m}$-wide columns were counted over an extent of at least $1 \mathrm{~mm}$. For each method, those somata intersecting the right-hand line were counted while those intersecting the left-hand line were disregarded. Only somata greater than $8 \mu \mathrm{m}$ in diameter were counted because we found in semithin plastic sections that the smallest neurons sectioned through their nuclei were of this size.

The tangentially cut sections through the occipital operculum that had been stained immunocytochemically for GABA were compared with adjacent sections stained for $\mathrm{CO}$. From photomicrographs enlarged to a final magnification of 480 , the outlines of the darkly stained $\mathrm{CO}$ patches in layers II and III (Horton and Hubel, 1981) and of prominent blood vessels were traced onto acetate sheets. The sheets were then placed over the micrographs of GABA-stained sections, the blood vessel contours aligned, and the densities of cells within areas corresponding to the CO patches determined with the Zidas tablet. Software was employed that allowed the area taken up by blood vessels to be subtracted from the area of a patch. The density of GABA-positive cells in regions 


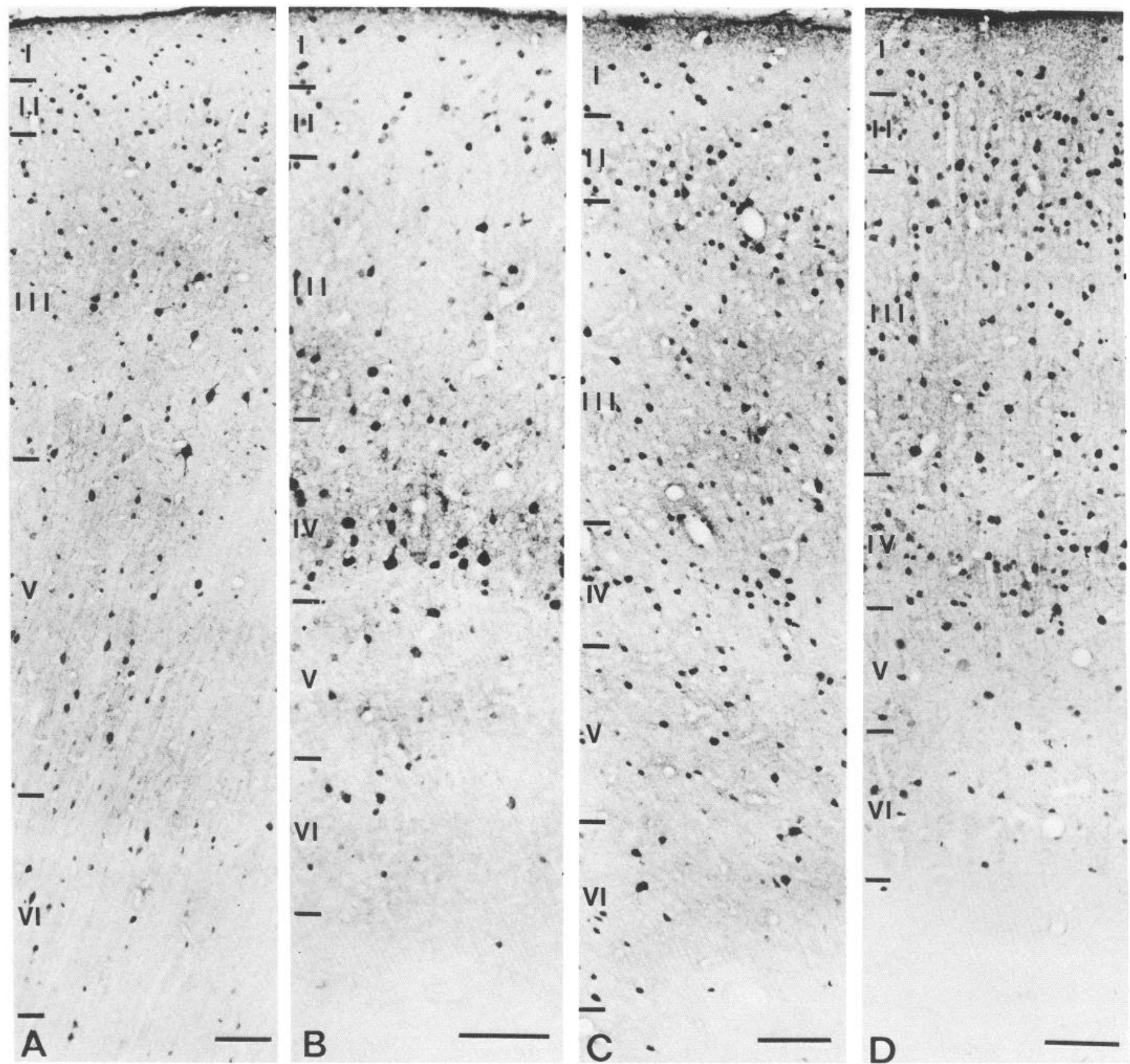

Figure 1. Photomicrographs of GABA-immunoreactive neurons in area $4(A)$, area $3 \mathrm{~b}(B)$, area $7(C)$, and area $18(D)$. In each area, GABApositive cells are present in all layers and are densest in layer II. In areas $3 \mathrm{~b}, 7$, and 18, relatively high concentrations are also present in the middle layers, but in area 4 , the number of stained neurons declines sharply from layer II to layer III and remains low through layer VI. $A$ is at a lower magnification and $B$ at a higher magnification than $C$ and $D$. Bars, $100 \mu \mathrm{m}$.

between the $\mathrm{CO}$ patches was determined in the same way. We examined interpatch spaces that ran parallel to the rows of $\mathrm{CO}$ patches and those that separated patches within a row.

Depth and laminar analyses. Photographic montages made at a final magnification of 480 were divided into horizontal rectangles that were $500 \mu \mathrm{m}$ wide, parallel to the cortical surface, and $50 \mu \mathrm{m}$ deep. The GABA-positive cells were counted in rectangles that collectively extended through the full thickness of each area and for $200 \mu \mathrm{m}$ into the white matter. In a separate set of montages, also at a magnification of 480 , layers were determined by matching the photomicrographs of GABA-stained sections with those of adjacent thionin-stained sections. Laminar boundaries were then drawn onto the montages, and the density of GABA neurons in each layer was determined with the Zidas tablet.
Proportions. Two methods were used to calculate the proportions of GABA-positive cells in 50- $\mu$ m-wide columns through the thickness of an area. One was an estimation based on the quotient of GABA-positive cells determined for one section and the total neuronal population determined for the adjacent section of equal thickness. Using methods identical to those for counting GABA-immunoreactive neurons (method 3, above), the total number of neurons in 50- $\mu \mathrm{m}$-wide columns was determined by examining thionin-stained sections in the microscope at $\times 1250$ and counting those neurons with nuclei in the section. For the purposes of recognizing the cell nuclei, $15 \mu \mathrm{m}$ was the thickest usable section, particularly when it came to examining the cell-dense layer IV of areas $3 \mathrm{~b}$ and 17 . The total number of neurons in a $50 \mu \mathrm{m}$ column was then divided into the number of GABA-positive neurons in the column of the same size. At this thickness and magnification, neuronal 


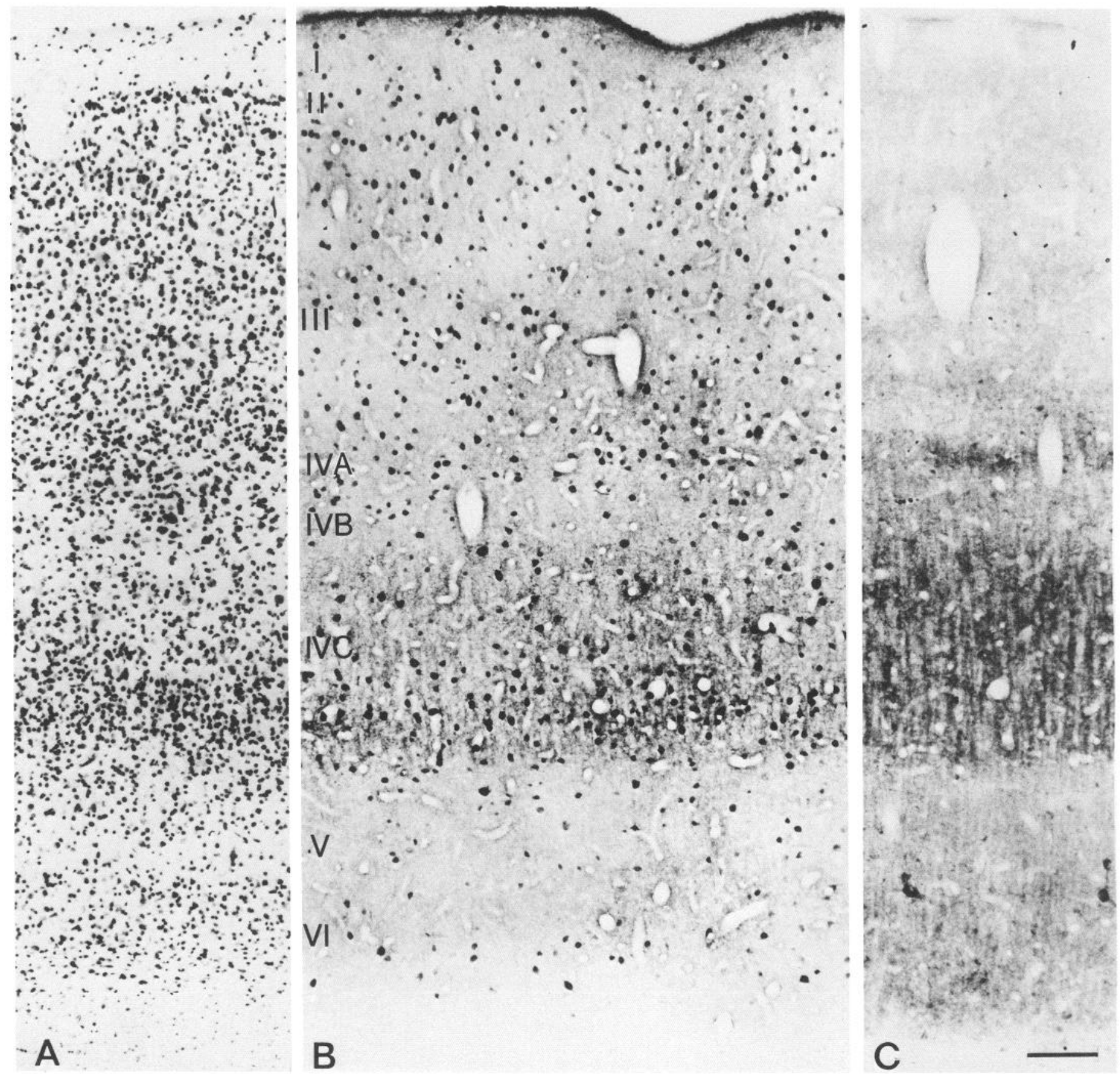

Figure 2. Photomicrographs of sections through area 17 stained with thionin $(A)$, for GABA $(B)$, and for cytochrome oxidase $(C)$. Dense concentrations of GABA-positive neurons are present in layers II-III, IVA, and IVC, with fewer cells stained in layers IBV, V, and VI. The density of GABA-positive neurons subdivides layer IVC into a superficial half with a lower density of cells and a deeper half with a higher density.

nuclei could be distinguished from those of neuroglial cells by their sizes and morphologies.

Direct measures of GABA cell proportions were made by examining semithin (1- $\mu$ m-thick) plastic sections of GABA-stained and methylene blue-Azur II-counterstained material. The sections were examined at a magnification of 1250 , and the total number of neurons and the number of GABA-positive neurons sectioned through their nuclei were counted for $50-\mu \mathrm{m}$-wide columns, as described above. At least 20 columns from each area were counted for every monkey.

Depth and laminar analyses, as described above for GABA cell counts, were also made for proportions by tracing GABA-positive and counterstained somata onto paper with the use of a camera lucida. The tracings were divided into rectangles with depths of $50 \mu \mathrm{m}$ or separated into their component layers and the proportions of GABA-positive cells for each were determined.

\section{Calculation of tissue shrinkage}

The amount of tissue shrinkage that occurred during immunocytochemical processing was determined by dividing the brain, as it was removed from the skull, into $1-\mathrm{cm}$-thick blocks and then photographing the blocks. The distance from the pial surface to the white matter and distances between other easily identifiable features (e.g., large blood vessels) were determined from each photograph and were compared with the distances between the same landmarks in sections from the block faces after they had been fully processed. 

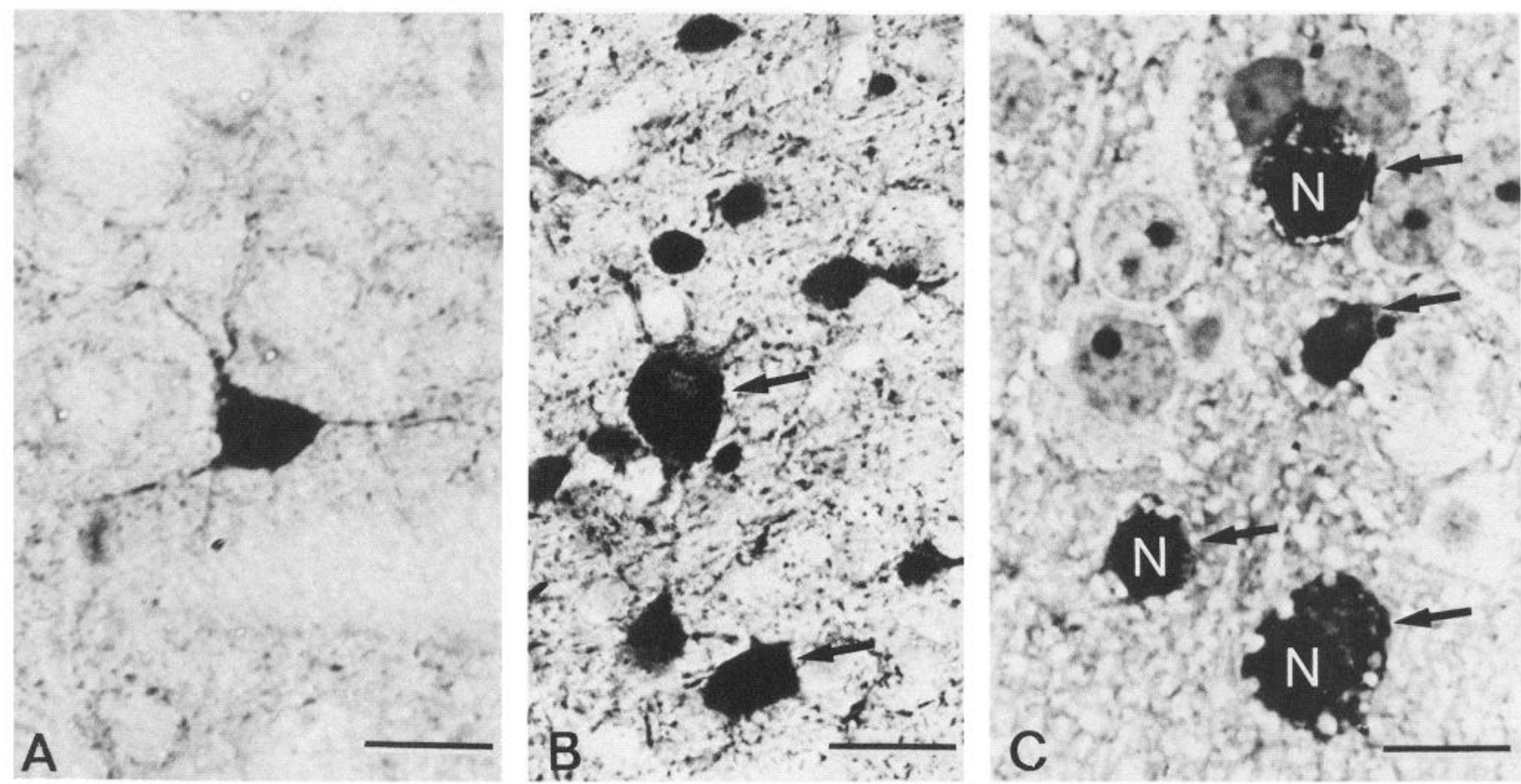

Figure 3. Photomicrographs of neurons in monkey cerebral cortex stained immunocytochemically for GABA. A, Vibratome section from area 4. The processes of GABA-positive cells are stained and the nonpyramidal morphology of the neurons is clear. Bar, $12 \mu \mathrm{m}$. $B$, Frozen section from area 4. GABA-immunoreactive cells include some neurons with large somata (arrows) and many others with smaller somata. Bar, $20 \mu \mathrm{m}$. $C$, Semithin plastic section from area 17 stained for GABA and counterstained with methylene blue and Azur II. Numerous GABA-stained neurons (arrows) are present and those with nuclei $(N)$ cut in the section are evident. Bar, $12 \mu \mathrm{m}$.

\section{Stereological analyses}

The numbers of GABA neurons within $1 \mathrm{~mm}^{3}$ of cortex and the numbers underlying imaginary squares of the cortical surface, measuring $1 \times 1$ $\mathrm{mm}$ or $50 \times 50 \mu \mathrm{m}$ were calculated for areas $4,3 \mathrm{~b}, 1-2,5$, and 17 . One-micron-thick plastic sections were examined at a magnification of 1250 and the nuclei of GABA-stained neurons in 50- $\mu \mathrm{m}$-wide columns through the cortical thickness were traced, using the camera lucida in the conventional manner. The columns extended from the pial surface to $200 \mu \mathrm{m}$ into the white matter. For all areas, 100 columns ( 5 columns in each of 20 sections) were examined from each of 2 monkeys. Both the areas and the long axes of the nuclei were measured on the Zidas tablet, and the short axes were calculated from these measurements (see O'Kusky and Colonnier, 1982). Using the nuclei as test objects, the number of GABA-immunoreactive neurons per $\mathrm{mm}^{3}$ was calculated by the formula for ellipsoids (Weibel, 1969; Weibel and Bolender, 1973), as detailed by O'Kusky and Colonnier (1982). The number of neurons underlying $1 \mathrm{~mm}^{2}$ of cortical surface was calculated by multiplying neuronal volume by the thickness of the cortex, as measured from the sections; the number underlying a $50 \times 50 \mu \mathrm{m}$ square was calculated by dividing the number under $1 \mathrm{~mm}^{2}$ by 400 .

\section{Results}

\section{Qualitative observations}

GABA-immunoreactive neurons were examined in detail in 7 areas of monkey cerebral cortex. These areas included 2 homotypical areas of the parietal lobe (areas 5 and 7), the agranular precentral motor area (area 4), 2 granular sensory areas (area $3 \mathrm{~b}$ of the first somatosensory cortex and area 17 of the visual cortex), and adjacent areas of the somatosensory (areas 1-2) and visual cortex (area 18). Limited analyses were made of area 21 of the temporal cortex and of the orbital and lateral frontal areas. Within each area, GABA-positive neurons were present in all layers and in the subcortical white matter (Figs. 1, 2) but tended to be concentrated in certain layers. Differences in the number and laminar distribution of GABA neurons between neighbor- ing areas (e.g., areas 17 and 18) clearly marked the borders between these areas.

In most of our sections, cut frozen at $15 \mu \mathrm{m}$, the processes of immunoreactive neurons were unstained. By contrast, both somata and processes were well stained in thicker sections cut on a Vibratome (Fig. 3). These neurons were exclusively nonpyramidal in morphology, with rounded somata and long, branching processes that emerge from the cell bodies at many points. Within some areas, particularly the sensorimotor cortex, large $(>15$ $\mu \mathrm{m}$ in somal diameter), GABA-positive cells with numerous stained dendrites could be distinguished among a greater number of small cells with few stained dendrites (Fig. $3 B$ ).

\section{Quantification of $G A B A$ neurons in narrow columns}

Quantitative analyses were performed on the 5 monkeys perfused with relatively low glutaraldehyde concentrations $(0.1-$ $0.4 \%$ ). The staining in the 6 th monkey, perfused with $2.5 \%$ glutaraldehyde, was markedly uneven (see below) and was not included in the analyses.

The numbers of GABA-immunoreactive neurons were determined for $50-\mu \mathrm{m}$-wide columns through each of 10 areas. The means for a particular area and animal were the same for each of the counting methods used (Table 1). Results show that the same number of GABA-immunoreactive cells were present in narrow columns through most areas. For areas 4, 1-2, 5, 7, and 18 , a mean of $34-43$ cells was found for a $50-\mu$ m-wide column. By contrast, both of the granular sensory areas $(3 \mathrm{~b}$ and 17) differed significantly from the others. A much larger number of GABA-positive neurons was found in area 17 of the monkeys we examined. The difference is a statistically significant increase of $50 \%$ in the numbers of stained cells as compared with other areas, including the adjacent area 18 (Duncan's multiple range 
Table 1. Mean number $( \pm \mathrm{SD})$ of GABA-immunoreactive neurons per 50- $\mu \mathrm{m}$-wide column through the thickness of areas $4,3 \mathrm{~b}, 1-2,5,7,18$ and 17

\begin{tabular}{|c|c|c|c|c|c|c|}
\hline \multirow[b]{2}{*}{ Area } & \multicolumn{3}{|l|}{ CM 181} & \multicolumn{3}{|l|}{ CM 187} \\
\hline & $\overline{\mathrm{A}}$ & B & $\mathrm{C}$ & $\overline{\mathrm{A}}$ & B & $\mathrm{C}$ \\
\hline 4 & $38.8 \pm 3.1$ & $37.6 \pm 3.7$ & $39.0 \pm 2.9$ & $40.1 \pm 2.9$ & $40.7 \pm 3.7$ & $39.4 \pm 2.7$ \\
\hline $3 b$ & $38.7 \pm 2.6$ & $38.0 \pm 3.3$ & $39.9 \pm 2.8$ & $33.4 \pm 4.0$ & $32.0 \pm 4.9$ & $32.1 \pm 3.9$ \\
\hline $1-2$ & $41.2 \pm 2.9$ & $39.1 \pm 3.9$ & $40.1 \pm 2.6$ & $39.6 \pm 2.7$ & $40.7 \pm 3.8$ & $38.4 \pm 2.1$ \\
\hline 5 & $39.6 \pm 2.4$ & $39.1 \pm 3.2$ & $40.4 \pm 2.2$ & $40.1 \pm 3.1$ & $38.1 \pm 4.1$ & $39.3 \pm 2.4$ \\
\hline 7 & $38.3 \pm 3.1$ & $41.0 \pm 3.1$ & $38.4 \pm 2.9$ & $38.1 \pm 2.6$ & $41.3 \pm 2.2$ & $40.4 \pm 3.7$ \\
\hline 18 & $39.4 \pm 3.0$ & $37.9 \pm 2.2$ & $38.1 \pm 2.9$ & $38.7 \pm 3.9$ & $40.1 \pm 2.2$ & $38.6 \pm 3.6$ \\
\hline \multirow[t]{2}{*}{17} & $60.3 \pm 5.3$ & $58.2 \pm 6.1$ & $59.1 \pm 5.7$ & $60.8 \pm 5.9$ & $59.1 \pm 6.9$ & $61.2 \pm 4.6$ \\
\hline & \multicolumn{3}{|l|}{ CM 183} & \multicolumn{3}{|l|}{ CM 189} \\
\hline Area & $\overline{\mathrm{A}}$ & B & $\mathrm{C}$ & $\overline{\mathrm{A}}$ & B & $\mathrm{C}$ \\
\hline 4 & $39.1 \pm 2.3$ & $38.1 \pm 3.6$ & $40.4 \pm 3.9$ & $38.1 \pm 2.9$ & $39.0 \pm 3.5$ & $39.4 \pm 2.4$ \\
\hline $3 b$ & $34.2 \pm 5.0$ & $35.1 \pm 6.3$ & $33.1 \pm 5.0$ & $39.4 \pm 2.1$ & $39.4 \pm 2.5$ & $40.1 \pm 3.0$ \\
\hline $1-2$ & $37.4 \pm 3.1$ & $36.2 \pm 3.8$ & $38.0 \pm 3.3$ & $38.6 \pm 3.3$ & $39.1 \pm 3.8$ & $38.4 \pm 3.3$ \\
\hline 5 & $38.7 \pm 2.6$ & $39.4 \pm 3.1$ & $39.1 \pm 2.7$ & $39.7 \pm 3.0$ & $38.4 \pm 4.3$ & $38.5 \pm 3.9$ \\
\hline 7 & $39.1 \pm 3.0$ & $38.6 \pm 4.1$ & $39.9 \pm 2.9$ & $40.1 \pm 2.7$ & $38.6 \pm 3.7$ & $41.4 \pm 2.7$ \\
\hline 18 & $37.7 \pm 3.1$ & $39.1 \pm 4.2$ & $38.4 \pm 3.9$ & $36.9 \pm 3.3$ & $39.7 \pm 3.7$ & $41.0 \pm 2.1$ \\
\hline \multirow[t]{2}{*}{17} & $59.7 \pm 4.0$ & $60.1 \pm 5.3$ & $61.1 \pm 4.7$ & $59.4 \pm 5.6$ & $60.1 \pm 6.7$ & $60.7 \pm 7.7$ \\
\hline & \multicolumn{3}{|l|}{ CM 184} & & & \\
\hline Area & $\bar{A}$ & B & $\mathrm{C}$ & & & \\
\hline 4 & $38.6 \pm 3.0$ & $41.4 \pm 5.0$ & $40.7 \pm 3.4$ & & & \\
\hline $3 b$ & $33.9 \pm 5.1$ & $34.1 \pm 5.2$ & $33.0 \pm 4.7$ & & & \\
\hline $1-2$ & $38.4 \pm 2.7$ & $39.7 \pm 3.4$ & $40.1 \pm 3.0$ & & & \\
\hline 5 & $39.4 \pm 2.2$ & $39.0 \pm 3.6$ & $40.4 \pm 2.0$ & & & \\
\hline 7 & $40.4 \pm 2.7$ & $40.1 \pm 3.9$ & $40.7 \pm 2.8$ & & & \\
\hline 18 & $38.6 \pm 3.7$ & $41.4 \pm 4.4$ & $40.8 \pm 5.0$ & & & \\
\hline 17 & $57.8 \pm 4.8$ & $60.0 \pm 5.7$ & $61.3 \pm 5.0$ & & & \\
\hline
\end{tabular}

Counts were made from photomicrographic montages at a final magnification of either 480 (A) or 960 (B) or directly from the microscope at a magnification of $1250(\mathrm{C})$.

test, $p<0.01$ ). Both the foveal representation and representation of the retinal periphery contained this larger number of GABA-positive neurons. No attempt was made to identify the representation of the monocular crescent and examine it separately.

A marked reduction in GABA-positive cells was seen in area $3 \mathrm{~b}$ in 3 out of the 5 monkeys we studied (Duncan's multiple range test, $p<0.05$ ). For the 3 (CM 183,184, and 187), the range of counts for individual columns was greater in area $3 \mathrm{~b}$ than in other areas (a minimum of 26 cells/column and a maximum of 42 cells/column) and results in means that were $25 \%$ less than those seen in the adjacent areas 4 and 1-2 (Table 1).
The other 2 monkeys displayed narrower ranges in area $3 \mathrm{~b}$ (minimum, 34; maximum, 43), and the means did not differ significantly from those in the other areas of sensorimotor and parietal association cortex. Within individual monkeys, the counts in area $3 \mathrm{~b}$ were the same for different parts of the body representation (Table 2 ).

When the proportions of neurons displaying GABA immunoreactivity are determined, the cortical areas outside area $3 b$ form 2 groups (Tables 3 and 5). In area 17, the GABA-positive cells made up approximately $20 \%$ of the neuronal population in all monkeys examined; for the remaining areas of cortex, $25 \%$ of the neurons were consistently found to be GABA immuno-

Table 2. Mean number ( $\pm \mathrm{SD}$ ) of GABA-immunoreactive neurons per $50-\mu \mathrm{m}$-wide column through the thickness of area $\mathbf{3 b}$

\begin{tabular}{|c|c|c|c|c|c|c|}
\hline & \multicolumn{2}{|l|}{ CM181 } & \multicolumn{2}{|l|}{$\mathrm{CM} 183$} & \multicolumn{2}{|l|}{ CM 189} \\
\hline & $\mathrm{A}$ & $\mathrm{B}$ & $\mathrm{A}$ & B & $\mathrm{A}$ & B \\
\hline Face & $38.0 \pm 2.1$ & $38.6 \pm 2.9$ & $35.7 \pm 5.4$ & $33.7 \pm 5.7$ & $39.1 \pm 2.9$ & $39.2 \pm 3.8$ \\
\hline Hand, arm & $38.9 \pm 2.8$ & $36.0 \pm 2.7$ & $34.7 \pm 6.0$ & $33.1 \pm 6.4$ & $38.7 \pm 2.8$ & $41.4 \pm 2.5$ \\
\hline Trunk & $36.6 \pm 3.0$ & $37.1 \pm 3.1$ & $32.0 \pm 6.1$ & $33.4 \pm 6.1$ & $39.4 \pm 3.3$ & $38.0 \pm 3.4$ \\
\hline Foot, leg & $37.4 \pm 2.9$ & $37.4 \pm 3.4$ & $35.8 \pm 5.5$ & $33.4 \pm 5.9$ & $39.6 \pm 4.1$ & $38.7 \pm 2.2$ \\
\hline
\end{tabular}

Counts were made from sections that were determined from their topography to contain the representation of the face, hand and arm, trunk, or foot and leg. Stained cells were counted from photomicrographic montages at a final magnification of either 480 (A) or 960 (B). 
Table 3. Mean number $( \pm \mathrm{SD})$ of GABA-immunoreactive neurons and of all thionin-stained neurons per 50- $\mu$ m-wide column through the thickness of areas $4,3 \mathrm{~b}, 1-2,5,7,18$, and 17

\begin{tabular}{|c|c|c|c|c|c|c|}
\hline \multirow[b]{2}{*}{ Area } & \multicolumn{3}{|l|}{ CM 181} & \multicolumn{3}{|l|}{ CM 187} \\
\hline & GABA & Total & $\%$ & GABA & Total & $\%$ \\
\hline 4 & $39.0 \pm 2.9$ & $158.9 \pm 16.1$ & $24.5 \pm 2.0$ & $39.4 \pm 2.7$ & $159.4 \pm 16.3$ & $24.5 \pm 1.3$ \\
\hline $3 b$ & $39.9 \pm 2.8$ & $152.7 \pm 11.9$ & $26.1 \pm 1.7$ & $32.1 \pm 5.9$ & $154.9 \pm 11.7$ & $20.6 \pm 1.2$ \\
\hline $1-2$ & $40.1 \pm 2.6$ & $154.8 \pm 14.2$ & $25.9 \pm 1.8$ & $38.4 \pm 4.0$ & $157.9 \pm 16.1$ & $24.4 \pm 2.1$ \\
\hline 5 & $40.4 \pm 2.2$ & $163.1 \pm 10.6$ & $24.7 \pm 2.3$ & $39.2 \pm 2.0$ & $160.6 \pm 14.1$ & $24.4 \pm 1.9$ \\
\hline 7 & $38.4 \pm 2.9$ & $158.2 \pm 9.4$ & $24.1 \pm 1.6$ & $40.7 \pm 3.7$ & $158.8 \pm 14.8$ & $25.1 \pm 1.4$ \\
\hline 18 & $38.1 \pm 2.9$ & $157.3 \pm 10.1$ & $24.4 \pm 2.1$ & $38.6 \pm 3.6$ & $157.9 \pm 15.0$ & $24.7 \pm 2.1$ \\
\hline \multirow[t]{2}{*}{17} & $59.1 \pm 5.7$ & $315.7 \pm 19.4$ & $18.7 \pm 2.1$ & $58.2 \pm 5.7$ & $309.9 \pm 22.7$ & $19.2+2.0$ \\
\hline & \multicolumn{3}{|l|}{ CM 183} & \multicolumn{3}{|l|}{ CM 189} \\
\hline Area & GABA & Total & $\%$ & GABA & Total & $\%$ \\
\hline 4 & $40.4 \pm 3.9$ & $161.7 \pm 15.3$ & $25.0 \pm 1.7$ & $39.4 \pm 2.4$ & $161.6 \pm 17.0$ & $24.3 \pm 2.1$ \\
\hline $3 b$ & $33.1 \pm 5.0$ & $157.9 \pm 12.2$ & $21.0 \pm 2.1$ & $40.1 \pm 3.0$ & $156.5 \pm 12.7$ & $25.6 \pm 2.3$ \\
\hline $1-2$ & $38.0 \pm 3.3$ & $154.3 \pm 11.6$ & $24.6 \pm 2.3$ & $38.4 \pm 3.3$ & $158.8 \pm 11.9$ & $24.0 \pm 1.9$ \\
\hline 5 & $39.1 \pm 2.7$ & $155.3 \pm 9.4$ & $25.2 \pm 1.8$ & $38.5 \pm 3.4$ & $155.1 \pm 12.0$ & $24.9 \pm 2.0$ \\
\hline 7 & $39.9 \pm 2.9$ & $157.6 \pm 11.8$ & $25.3 \pm 1.3$ & $40.4 \pm 2.4$ & $160.1 \pm 16.5$ & $25.2 \pm 2.4$ \\
\hline 18 & $38.4 \pm 3.9$ & $152.0 \pm 9.1$ & $25.3 \pm 1.6$ & $38.1 \pm 2.9$ & $157.5 \pm 17.5$ & $24.2 \pm 1.7$ \\
\hline \multirow[t]{2}{*}{17} & $61.1 \pm 4.7$ & $309.8 \pm 17.1$ & $19.6 \pm 1.5$ & $59.1 \pm 5.7$ & $321.3 \pm 23.6$ & $18.5 \pm 2.2$ \\
\hline & \multicolumn{3}{|l|}{ CM 184} & & & \\
\hline Area & GABA & Total & $\%$ & & & \\
\hline 4 & $40.7 \pm 3.4$ & $157.1 \pm 15.5$ & $25.2 \pm 1.1$ & & & \\
\hline $3 b$ & $32.9 \pm 5.7$ & $160.4 \pm 11.0$ & $20.2 \pm 1.9$ & & & \\
\hline $1-2$ & $40.1 \pm 3.1$ & $154.9 \pm 9.7$ & $25.1 \pm 1.7$ & & & \\
\hline 5 & $40.4 \pm 2.0$ & $158.1 \pm 13.0$ & $24.9 \pm 1.3$ & & & \\
\hline 7 & $40.7 \pm 2.8$ & $159.9 \pm 11.7$ & $24.3 \pm 2.0$ & & & \\
\hline 18 & $40.8 \pm 5.0$ & $158.4 \pm 16.2$ & $24.7 \pm 1.8$ & & & \\
\hline 17 & $60.3 \pm 5.3$ & $319.6 \pm 21.4$ & $19.1 \pm 1.0$ & & & \\
\hline
\end{tabular}

Counts of GABA-positive neurons and of all neurons were made at a magnification of 1250 from adjacent sections, and the percentages of GABA cells were calculated from the quotient of the 2 values.

reactive. Neither the total number of neurons nor the number of GABA neurons differed significantly among areas 4, 1-2, 5, 7 , and 18 (Duncan's multiple range test). With both methods used to calculate the proportion of GABA neurons (see Materials and Methods), we found 1 out of every 4 neurons in each area to be stained immunocytochemically for GABA. The lower percentage in area 17 was found despite the greater number of GABA neurons in this area (see above), a result being due to the even larger increase in the total number of neurons (Table $3)$.
For area $3 b$, the proportion of cells displaying GABA immunoreactivity varied among individual animals. In 3 monkeys, slightly more than $20 \%$ of the neurons in area $3 \mathrm{~b}$ were immunoreactive for GABA, but in the remaining 2 , the greater number of GABA neurons present (see above) raised the proportion to $25 \%$. For each monkey, the maximum percentage of GABA neurons per $50-\mu \mathrm{m}$-wide column was the same, but in the monkeys displaying a lower overall percentage, many columns contained a significantly lower proportion of GABA neurons. These 5 monkeys were treated and processed with the

Table 4. Mean number ( \pm SD) of GABA-immunoreactive neurons and of all thionin-stained neurons in $50-\mu \mathrm{m}$-wide columns through the thickness of area 21 of the temporal lobe and areas of orbital frontal and lateral frontal cortex

\begin{tabular}{|c|c|c|c|c|c|c|}
\hline & \multicolumn{3}{|l|}{ CM 181} & \multicolumn{3}{|l|}{ CM 189} \\
\hline & GABA & Total & $\%$ & GABA & Total & $\%$ \\
\hline Area 21 & $38.6 \pm 3.2$ & $161.4 \pm 10.4$ & $24.1 \pm 2.1$ & $38.1 \pm 3.6$ & $156.4 \pm 11.2$ & $24.4 \pm 2.2$ \\
\hline \multicolumn{7}{|l|}{ Inferior } \\
\hline frontal & $37.4 \pm 2.8$ & $157.6 \pm 9.0$ & $23.6 \pm 2.0$ & $39.6 \pm 4.0$ & $158.9 \pm 12.2$ & $24.8 \pm 2.9$ \\
\hline \multicolumn{7}{|l|}{ Lateral } \\
\hline frontal & $39.0 \pm 2.9$ & $163.1 \pm 12.7$ & $23.9 \pm 1.9$ & $40.6 \pm 2.6$ & $160.4 \pm 14.1$ & $25.1 \pm 2.5$ \\
\hline
\end{tabular}


Figure 4. Graphs showing the number of GABA-positive cells in 20-40 contiguous, $50-\mu \mathrm{m}$-wide columns through areas $3 b, 5,18$, and 17 . The counts were made from $15-\mu \mathrm{m}$-thick frozen sections through each area. Prominent peaks and valleys are evident in the densities of GABA neurons in these areas. In areas $3 \mathrm{~b}$ and 17 , the peaks are numerous and represent columns in which $20-30 \%$ more neurons are stained than in neighboring columns. In area 18 , bands of varying width (200-700 $\mu \mathrm{m})$ contain relatively high denstities of GABA neurons and alternate with narrow bands (100-200 $\mu \mathrm{m})$ containing a lower density of GABA neurons.

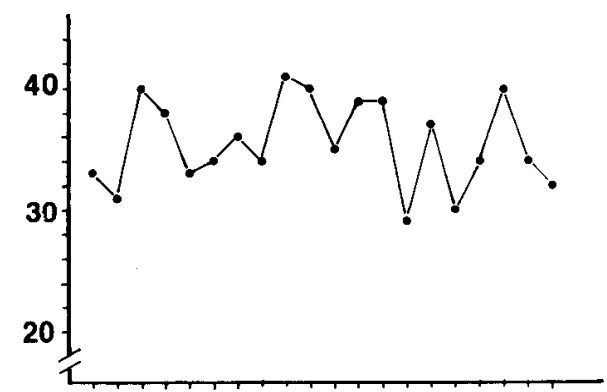

AREA 3b

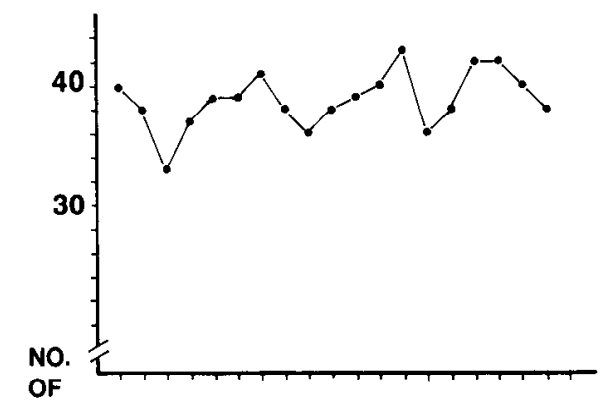

AREA 5
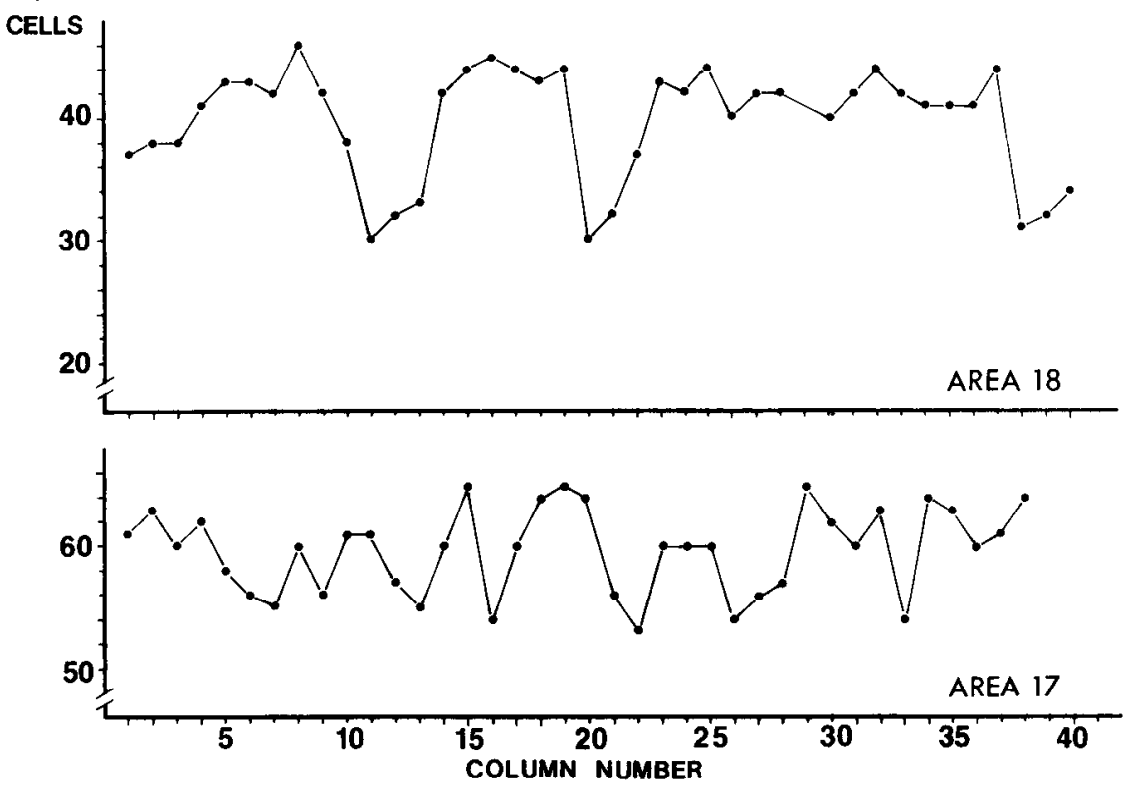

same methods, and the 2 with the higher percentages were perfused with the same fixative ( $2 \%$ paraformaldehyde and either $0.1 \%$ or $0.2 \%$ glutaraldehyde) and processed simultancously with monkeys containing fewer stained cells in area $3 \mathrm{~b}$.

Iimited analyses were also made of GABA cell numbers and proportions in 3 additional areas of cortex, area 21 of the temporal lobe and at constant points in the inferior frontal and lateral frontal areas (apex of the lateral frontal gyrus and flattest part of the lateral orbital gyrus). In 2 monkeys, the numbers of GABA-immunoreactive and thionin-stained neurons were determined for 50- $\mu \mathrm{m}$-wide columns. Similar numbers of GABApositive neurons were found in each of these areas, and they closely approximated the numbers present in most other areas of monkey cortex (Table 4). An estimate of the proportions of GABA-positive neurons in the 3 areas was calculated from the number of immunoreactive cells in $50 \mu \mathrm{m}$ columns of a section and the number of thionin-stained cells in the adjacent section. The estimated proportion of GABA-positive neurons in the 3 areas approached $25 \%$, the differences among these areas not being significant.

\section{Variability in numbers of GABA neurons within areas}

Although most areas had mean numbers of GABA neurons that did not vary from one section to another or from one monkey to another, there were substantial variations among individual $50-\mu \mathrm{m}$-wide columns (Fig. 4). As noted above, this variability was prominent in area $3 \mathrm{~b}$, where in some monkeys, almost $50 \%$ more neurons were present in the maximal count than in the minimal. In area $3 b$ of the other 2 monkeys and in the remaining areas of the sensorimotor cortex and in areas 17 and 18 , the variability among columns was smaller (20-30\%); in areas 5 and 7 , it amounted to less than $20 \%$.

We examined the intra-areal variability in a systematic fashion by making counts of $20-40$ contiguous $50-\mu$ m-wide columns through each area. Plotting the data in graphic form (Fig. 4), it becomes clear that most areas contain prominent peaks and 

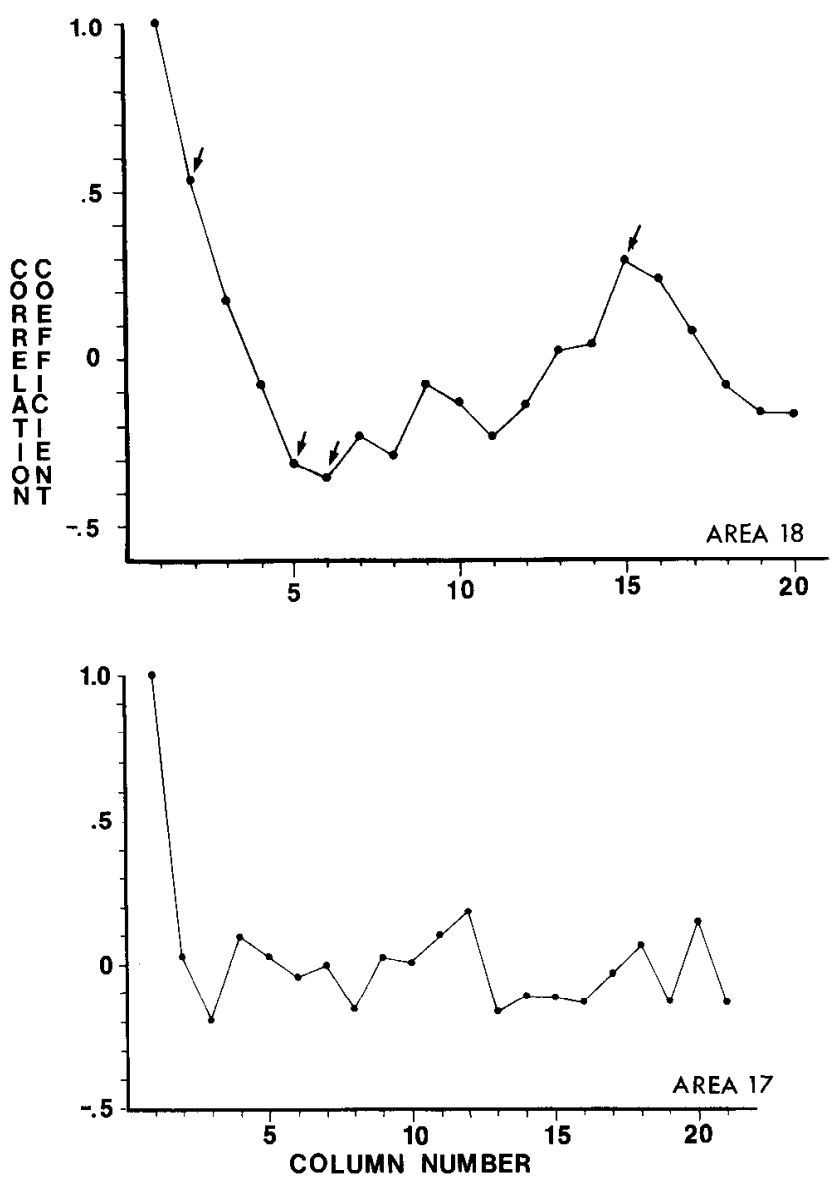

Figure 5. Autocorrelograms of the counts in contiguous columns through areas 17 and 18 shown in Figure 4. Four values in the area 18 counts (arrows), but none in the area 17 counts, display significant autocorrelation $(p<0.05$; the first value, generated by comparing each column with itself, is always a value of 1 ). Significant peaks and valleys in area 18 are separated from one another by distances of 100 and 450 $\mu \mathrm{m}$. The lack of significant correlations in area 17 indicates that the intra-areal variation adopts no regular pattern. Autocorrclograms for the other areas also failed to show significant correlations.

valleys in the numbers of GABA neurons and that the patterns formed vary among cortical areas. In most areas, the patterns are very irregular, but a more regular pattern is found in area 18 , where broad (600- to $700-\mu \mathrm{m}$-wide) plateaus and narrow (200- to $300-\mu \mathrm{m}$-wide) peaks containing many GABA-positive neurons alternate with narrow (100- to $200-\mu \mathrm{m}$-wide) valleys containing fewer immunoreactive neurons. To test for periodicities in these series of columns we used a stepwise autocorrelation procedure, in which a series of correlation coefficients is calculated between each member of the series of columns and every other member, sequentially shifted by $1,2,3 \ldots n$ steps, where $n$ is the total number of columns in the series (Harnett, 1982). Significant peaks are found only in the autocorrelogram for area 18, and even here the peaks are small (Fig. 5). However, the extents of cortex we examined were limited, and patterns with a repeating cycle greater than a millimeter of cortex would not be apparent in our analyses. No evidence of periodicities was found in area 18 when a randomly collected series of 50$\mu \mathrm{m}$-wide columns was analyzed.

The greatest variabilities in GABA cell numbers were noted in sections processed under conditions that we found to be less than optimal. Fixation with $2.5 \%$ glutaraldehyde, processing of
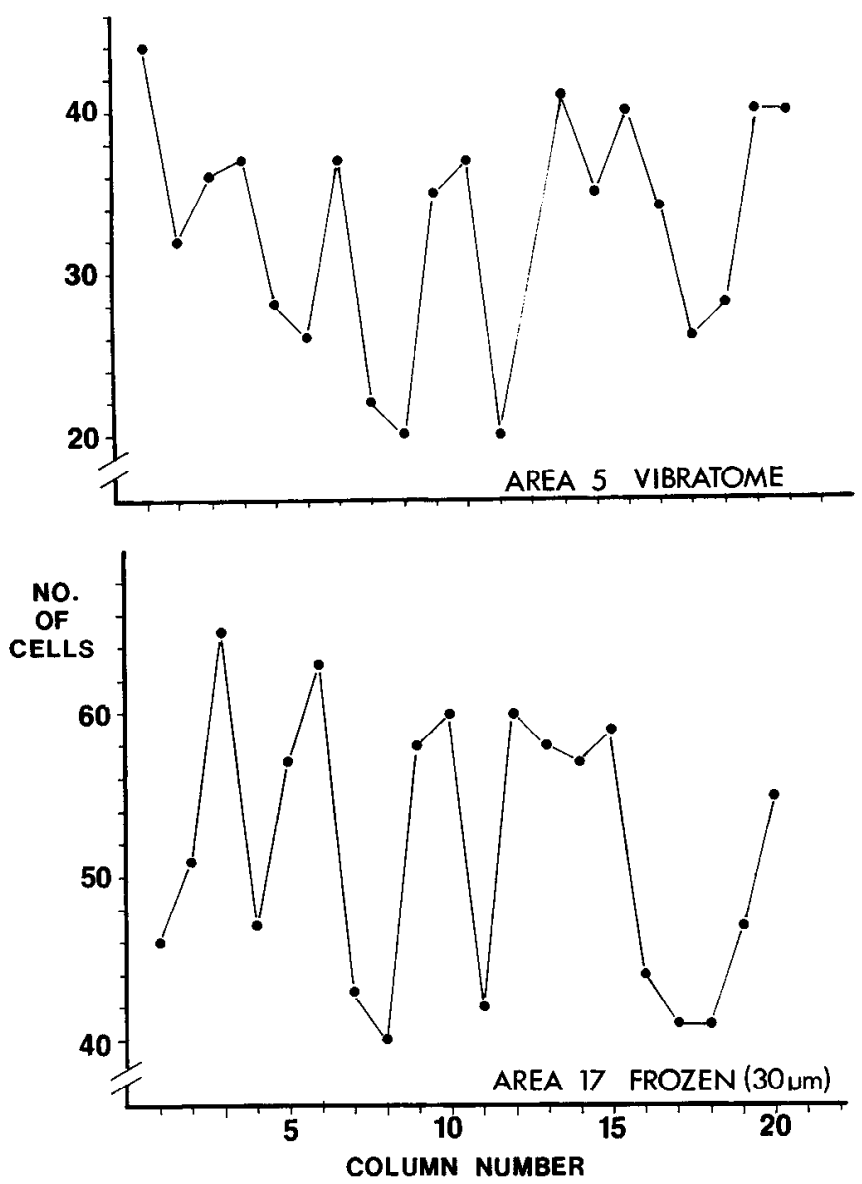

Figure 6. Graphs showing the distribution of GABA-immunoreactive neurons in contiguous columns through a $30-\mu \mathrm{m}$-thick section of area 5 , cut on a Vibratome, and through a $30-\mu$ m-thick frozen section of area 17 . The much greater variability seen in these sections than in the thinner frozen sections ( $c f$. Fig. 4) arises from markedly reduced numbers of cells in some columns.

thick ( $>20 \mu \mathrm{m}$ ) frozen sections or Vibratome sections, and incubating sections already mounted on slides produced marked variations in the numbers of GABA-positive neurons per column (Fig. 6). At irregular intervals in these sections, patches (100-500 $\mu \mathrm{m}$ wide) containing very few GABA-positive neurons (20 or fewer cells/column) were found, while in neighboring regions the cell numbers were the same as those seen in the thinner frozen sections. The patches of lesser staining were seen both in the banks of sulci and on the surfaces of the gyri, whilc the regions of better staining frequently surrounded large, penetrating blood vessels.

\section{Laminar distribution of GABA-immunoreactive neurons}

GABA-position neurons displayed an uneven laminar distribution in each of the areas examined (Figs. 1, 2). Two features of cortical GABA neuron distribution remained constant: (1) A small but consistent population of immunoreactive neurons was seen in layer I; and (2) at least half of the GABA neurons were present in the supragranular layers (I-III). When the laminar distributions were graphed for each area (Fig. 7), peaks in the numbers and densities of GABA-positive cells were always seen in layer II, while low numbers and densities were found in layers $\mathrm{V}$ and VI. The pattern in the middle layers varied among areas. In area 4 , the peaks in layer II were followed by progressive 

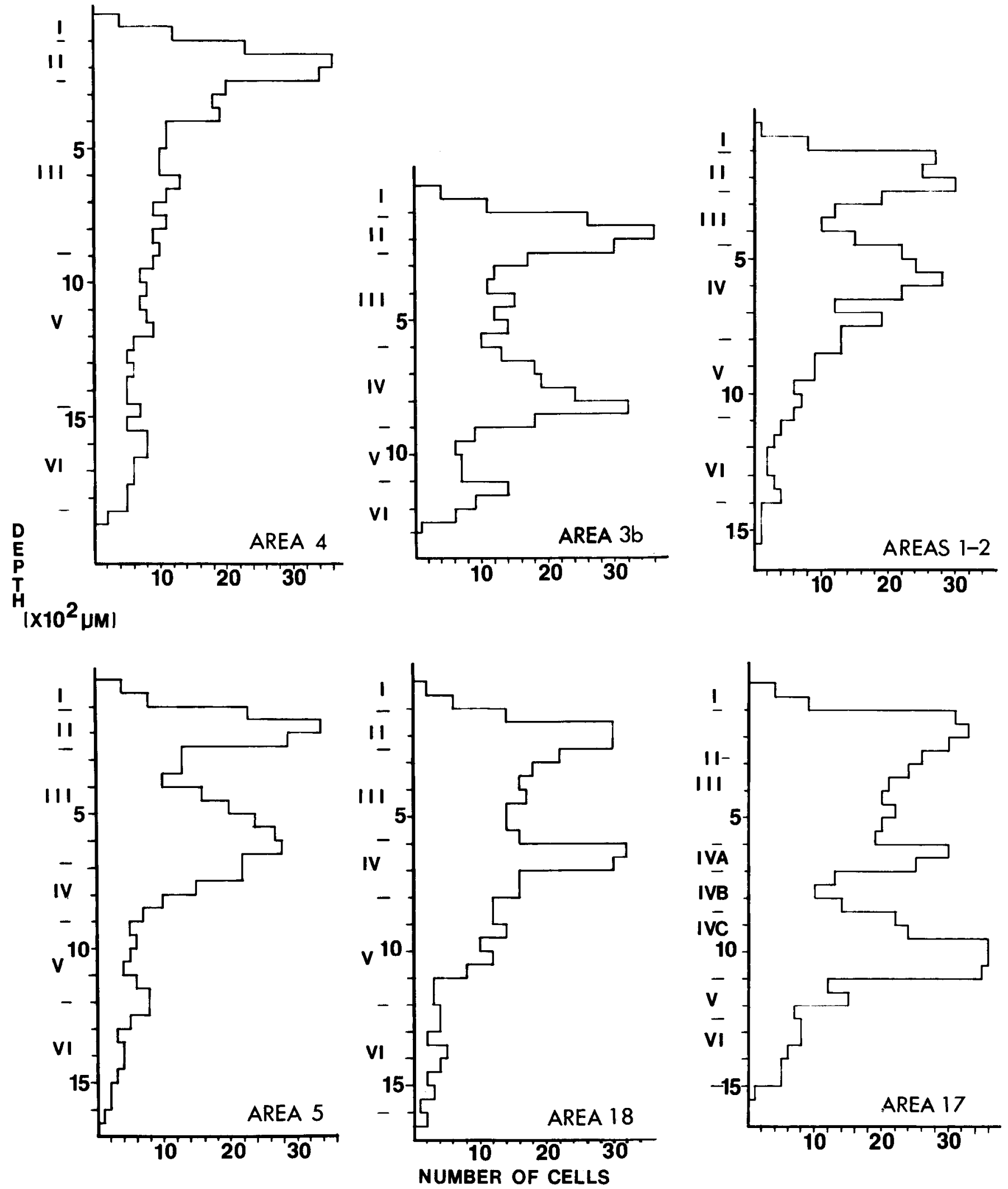

Figure 7. Depth profiles of the numbers of GABA cells in areas of monkey cortex. The counts represent the numbers of stained neurons in contiguous rectangles $500 \mu \mathrm{m}$ wide and $50 \mu \mathrm{m}$ deep through each area. High densities of cells are present at depths that correspond to layer II of each area and to middle layers in most areas. These include layer IV of areas $3 \mathrm{~b}$ and 18, layer III and superficial layer IV in areas 1-2 and 5, and layers IVA and IVC in area 17. Data illustrated are from single traverses through each area in CM 181. Similar graphs were generated by analyzing other traverses through the cortex of this monkey and through the cortex of the 4 other monkeys. 
declines in the numbers and densities of GABA-positive neurons throughout the rest of the layers. By contrast, second peaks were found in the middle layers of each other area and corresponded to layer IV in area $3 \mathrm{~b}$ and 18 and both layers IIIB and IV in areas 1-2, 5, and 7. The numbers and densities of GABApositive neurons were also higher in layers $\mathrm{V}$ and $\mathrm{VI}$ in area 18 than they were in other areas. Area 17 contained 2 peaks within layer IV: one was narrow and corresponded to layer IVA, and the other was broad and corresponded to layer IVC.

We analyzed the contribution of the different layers to the variations in cell number and density by breaking down values for 50- $\mu \mathrm{m}$-wide columns through the cortical thickness into their component laminar values. Our findings indicate that variations in some areas arise from variations in single layers. In area $3 b$, the numbers of GABA cells in the supra- and infragranular layers remained relatively constant, but the numbers in layer IV varied. We found the peaks and valleys in GABA cell numbers for layer IV to be positively correlated with peaks and valleys for the columns as a whole. By contrast, the variability in area 17 is correlated with differences in GABA cell numbers in layers II and III, and in area 18 with differences in layers IIIB and V. For the remaining areas no correlation could be found between columnar and laminar variations.

The proportion of GABA-immunoreactive neurons in each layer was determined from semithin plastic sections through the specified cortical areas in the 5 monkeys. GABA-positive neurons and unstained neurons in twenty $50-\mu \mathrm{m}$-wide columns were counted in each area of each monkey. Except for layer I, in which more than $90 \%$ of the neurons were GABA-immunoreactive, the range of proportions was relatively small, usually varying between 15 and $30 \%$ of the total neuronal population (Fig. 8). Within all areas except area 17 , approximately $30 \%$ of the neurons in the supragranular layers werc GABA immunoreactive. In a single monkey, the GABA cells in area 17 made up no more than $25 \%$ of the neuronal population in layers II and III and often as little as $20 \%$. The biggest difference among areas was seen in the proportion of GABA neurons in layer IV, which equaled $30 \%$ in some parts of area $3 \mathrm{~b}$ and $15 \%$ in areas 5 and 7. Similar variations in the percentages of layer IV GABA neurons were also found within area $3 \mathrm{~b}$ of some monkeys, since 50 - $\mu \mathrm{m}$-wide columns with a low $(15 \%)$ proportion in layer IV were as frequent as columns with a high $(30 \%)$ proportion. Even in those animals with a greater uniformity in proportions of GABA neurons, the percentages in layer IV of area $3 \mathrm{~b}$ varied from $20 \%$ in some columns to $30 \%$ in others. The variability within area $3 \mathrm{~b}$ arises not from differences in the total number of layer IV neurons among columns but from decreases in some columns of the number of GABA neurons in layer IV. Layer IV of area 17 displayed no variations among $50-\mu \mathrm{m}$-wide columns but was split into 3 major horizontal subdivisions, the most superficial of which (layer IVA) contained the highest percentage of GABA neurons (35\%), while the remaining 2 (layers IVB and IVC) had approximately half that percentage (15-20\%).

In most areas, a relatively small proportion of cells in layers $\mathrm{V}$ and VI were GABA-positive, usually $15 \%$ of the total neuronal
Figure 8. Graphs showing the proportions of GABA-immunoreactive neurons in individual layers through areas $4,3 \mathrm{~b}, 1-2,5,7,18$, and 17 of CM 189. The proportions were determined by counting twenty 50 $\mu \mathrm{m}$-wide columns in plastic sections through each area. GABA-positive neurons make up $90-100 \%$ of the neurons in layer I and $30-40 \%$ in
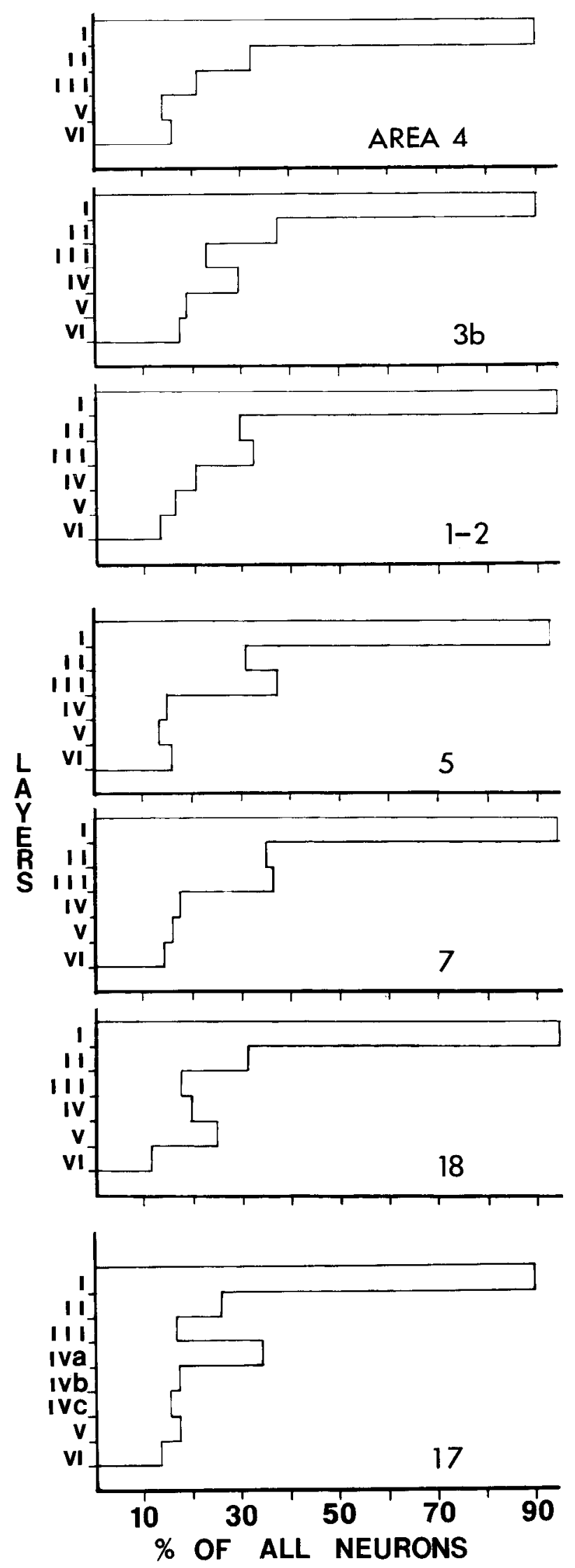

layer II but as little as $15 \%$ in layers V and VI of areas other than 18 (where $25 \%$ of the neurons are stained). In the middle layers, the highest proportions of GABA-positive neurons are in layer III of areas 5 and 7 and in layer IVA of area 17. Similar proportions were found for the other monkeys. 
Table 5. Mean percentage ( \pm SD) of the total GABA-immunoreactive neuronal population in 50- $\mu$ mwide columns through the thickness of areas $4,3 \mathrm{~b}, 1-2,5,7,18$, and 17

\begin{tabular}{llllll} 
Area & CM 181 & CM 183 & CM 184 & CM 187 & CM 189 \\
\hline 4 & $24.2 \pm 2.1$ & $25.6 \pm 1.2$ & $24.9 \pm 1.4$ & $25.1 \pm 1.2$ & $24.9 \pm 2.0$ \\
$3 \mathrm{~b}$ & $24.6 \pm 1.8$ & $20.3 \pm 2.8$ & $21.1 \pm 3.0$ & $20.7 \pm 2.7$ & $24.4 \pm 1.3$ \\
$1-2$ & $24.6 \pm 1.9$ & $24.4 \pm 2.1$ & $24.8 \pm 1.2$ & $25.1 \pm 1.9$ & $23.7 \pm 2.2$ \\
5 & $24.8 \pm 2.0$ & $25.2 \pm 1.4$ & $25.4 \pm 2.1$ & $24.9 \pm 1.4$ & $23.9 \pm 1.7$ \\
7 & $24.2 \pm 2.2$ & $24.6 \pm 1.9$ & $25.4 \pm 1.3$ & $24.9 \pm 2.5$ & $24.8 \pm 2.0$ \\
18 & $25.2 \pm 1.3$ & $25.4 \pm 1.9$ & $24.4 \pm 2.4$ & $23.7 \pm 2.4$ & $25.3 \pm 1.9$ \\
17 & $19.4 \pm 1.5$ & $19.1 \pm 1.7$ & $20.2 \pm 1.2$ & $19.7 \pm 1.5$ & $18.9 \pm 0.9$ \\
\hline
\end{tabular}

Counts were made of GABA-immunoreactive and nonimmunoreactive neurons with nuclei present in $1-\mu \mathrm{m}$-thick plastic sections. The percentage of GABA-positive neurons was calculated from these values.

population. However, in area 18 the GABA neurons in layer $\mathrm{V}$ varied from a small proportion of neurons over short stretches $(100-200 \mu \mathrm{m})$ to wider bands $(300-700 \mu \mathrm{m})$ where the immunoreactive cells exceeded $25 \%$ of the total population.

\section{Quantification of $G A B A$ neurons in tangential sections through area 17}

Although we failed to observe a regular, repeating pattern to the columnar variations within area 17 (see above), we nevertheless examined the density of GABA neurons in sections from 3 monkeys cut tangentially through the layers and correlated the density with the presence or absence of $\mathrm{CO}$-stained patches. The density of GABA neurons varied a great deal within individual sections through layers II and III of each monkey, even when depth was held constant by examining sections from a flattened block (Fig. 9). However, the presence of high and low values of GABA cell density is not correlated with the presence of CO-stained patches. Instead, both the patches and the interpatch spaces exhibit marked variations in cell density (Fig. 9), so that the means for the 2 regions are the same at any one depth, and the range of densities for both regions forms a normal distribution (Fig. 10). Both the variability in GABA cell density and its independence of the position of the $\mathrm{CO}$ patches is evident in the representation of the fovea and of the retinal periphery. A general trend exists within layers II and III, where a significantly greater number of GABA-positive neurons in both patches and interpatch spaces was found at more superficial levels (120 $\mu \mathrm{m}$ below the pial surface versus $280 \mu \mathrm{m}$ below the surface; Duncan's multiple range test, $p<0.05$ ). At $120 \mu \mathrm{m}$ below the surface, $1081.5 \pm 178.8 \mathrm{GABA}$-positive cells $/ \mathrm{mm}^{2}$ were present in the patches (mean $\pm \mathrm{SD}$ ), while $1015.7 \pm 242.7 \mathrm{GABA}$ positive cells were present between them. At $280 \mu \mathrm{m}$, patches had $692.6 \pm 152.4$ GABA-positive cells $/ \mathrm{mm}^{2}$ and interpatch regions, $716.3 \pm 135.5 \mathrm{GABA}$-positive cells $/ \mathrm{mm}^{2}$ (values from 1 monkey; 2 other monkeys gave similar values).

\section{Stereological analyses}

In areas $4,3 \mathrm{~b}, 1-2,5$, and 17 , the numbers of GABA neurons were calculated for cubes of cortex with sides of $1 \mathrm{~mm}$ and for the full thickness of cortex underlying surface squares of $1 \times 1$ $\mathrm{mm}$ or $50 \times 50 \mu \mathrm{m}$ (Table 6 ). For these calculations, we measured the amount of tissue shrinkage that had occurred during histological processing, which was found to vary from 29.3 to $32.7 \%$. We therefore employed a correction factor (see Materials and Methods and O'Kusky and Colonnier, 1982), determined separately for each block, to calculate the numbers of GABApositive neurons present in the unprocessed brain. In area 17, nearly 24,000 GABA-immunoreactive neurons were present within each cubic millimeter of cortex, while under $1 \mathrm{~mm}^{2}$ between 33,500 and 36,300 GABA-positive neurons were calculated to exist. This corresponds to 84-90 GABA neurons underlying a surface square of $50 \times 50 \mu \mathrm{m}$. In areas $4,1-2,3 \mathrm{~b}$, and 5 , fewer GABA neurons exist in $1 \mathrm{~mm}^{3}$ of cortex $(10,000$ 17,500 ) and, thus, fewer cells are found to underlie $1 \mathrm{~mm}^{2}$ $(19,500-24,500)$ or to exist within a column beneath a $50 \times 50$ $\mu \mathrm{m}$ square (50-61 neurons).

\section{Discussion}

Ûsing immunocytochemical methods to detect GABA neurons in several structurally and functionally distinct areas of monkey cerebral cortex, we found the same mean density and the same proportion relative to the total neuronal population in most areas. Only area 17 contains a higher density of GABA-immunoreactive neurons, and only it and possibly area $3 \mathrm{~b}$ contain a smaller proportion of these cells relative to the total neuronal population. However, differences do exist among areas in the

Table 6. Mean number ( \pm SD) of GABA-immunoreactive neurons calculated to be present in a volume of $1 \mathrm{~mm}^{3}$ or to underlie surface $1 \mathrm{~mm}^{2}$ or $50 \times 50 \mu \mathrm{m}$ squares

\begin{tabular}{|c|c|c|c|c|c|c|}
\hline \multirow[b]{2}{*}{ Area } & \multicolumn{2}{|l|}{ Count $/ \mathrm{mm}^{3}$} & \multicolumn{2}{|l|}{ Count $/ \mathrm{mm}^{2}$} & \multicolumn{2}{|c|}{ Count $/ 50 \times 50 \mu \mathrm{m}$} \\
\hline & $\mathrm{CM} 181$ & CM 187 & CM 181 & CM 187 & CM 181 & CM 187 \\
\hline 4 & $10,400 \pm 190$ & $11,200 \pm 210$ & $22,800 \pm 840$ & $24,100 \pm 990$ & $57.0 \pm 2.1$ & $60.3 \pm 2.5$ \\
\hline $3 b$ & $17,200 \pm 310$ & $14,900 \pm 270$ & $23,600 \pm 1100$ & $19,900 \pm 970$ & $59.0 \pm 3.8$ & $49.8 \pm 4.7$ \\
\hline $1-2$ & $16,100 \pm 210$ & $15,800 \pm 230$ & $24,200 \pm 1200$ & $23,800 \pm 1080$ & $60.5 \pm 3.3$ & $59.2 \pm 3.8$ \\
\hline 5 & $15,200 \pm 240$ & $14,600 \pm 230$ & $23,500 \pm 1050$ & $23,100 \pm 1160$ & $58.8 \pm 1.9$ & $57.8 \pm 2.3$ \\
\hline 17 & $23,160 \pm 390$ & $23,700 \pm 400$ & $34,500 \pm 1700$ & $36,300 \pm 1660$ & $86.3 \pm 7.0$ & $90.8 \pm 7.7$ \\
\hline
\end{tabular}

Calculations were made from measurements in $1-\mu$ m-thick plastic sections through the thickness of areas $4,3 b, 1-2,5,7,18$, and 17 . 

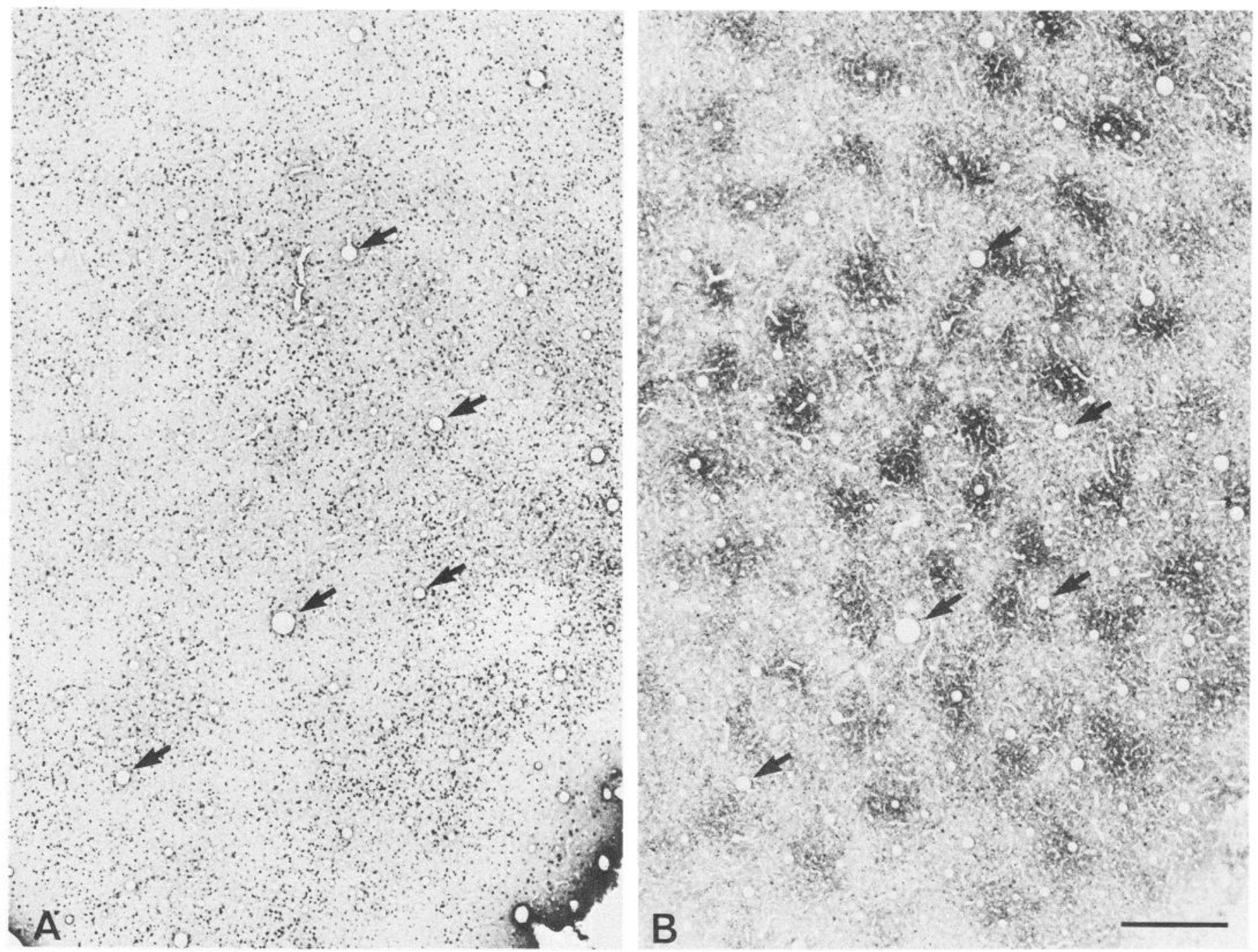

Figure 9. Photomicrographs of tangential sections primarily through layer III of area 17, stained for GABA $(A)$ and cytochrome oxidase, CO $(B)$. Many of the GABA-positive neurons in the superficial layers are clustered together into patches of different sizes; these are separated from one another by regions in which few cells are stained. The positions of the GABA cell clusters were compared with the positions of the CO-stained patches by noting the locations of the same radially oriented blood vessels (arrows) in the 2 sections. Some clusters of GABA cells coincide with $\mathrm{CO}$ patches, while others lie between patches. Thus, no consistent relationship exists betwen the numbers of GABA-immunoreactive somata and the positions of $\mathrm{CO}$ patches in superficial layers of area 17.

distribution of GABA neurons, and variations in density are found within individual areas. These data, detailing the number of GABA-positive cells in areas of the monkey cerebral cortex, will be discussed in the context of the limitations to quantifying immunocytochemically processed material, the evidence from previous quantitative studies of cortical neurons, and the contributions of GABA neurons to the organization of the cerebral cortex.

\section{Methodological considerations}

Our quantitative analyses of GABA neurons in the monkey cerebral cortex are based on the ability to stain these cells by immunocytochemistry. The analyses are valid if we have been able to stain all GABA neurons and only GABA neurons in the cortex, a goal we attempted to achieve by testing several methods and controls. Clearly, large numbers of neurons are stained by the methods we adopted and adjustments in those methods (changes in fixation, tissue preparation, and immunocytochem- ical processing) do not increase the numbers of GABA-positive neurons, while methods that proved less than optimal reduce the numbers. Nonetheless, several methodological problems inherent in immunocytochemistry might have left a significant population of GABA neurons undetected, even under optimal conditions. Foremost among these problems is the difficulty in getting the immunocytochemical reagents to penetrate into fixed tissue and thus stain all cells expressing a particular antigen. We attempted to overcome this problem as far as possible by cutting relatively thin $(15 \mu \mathrm{m})$ frozen sections and by using detergents, both of which aid antibody penetration. A second potential source of error is that chemical fixation of the tissue so altered some proportion of GABA molecules that they were not recognized by the primary antibodies, leaving undetected some cells containing low concentrations of GABA. This is unlikely with the antiserum we used since it was generated using glutaraldehyde-fixed GABA as an immunogen and, thus, recognized the fixed molecule. The continued presence of immunostaining 

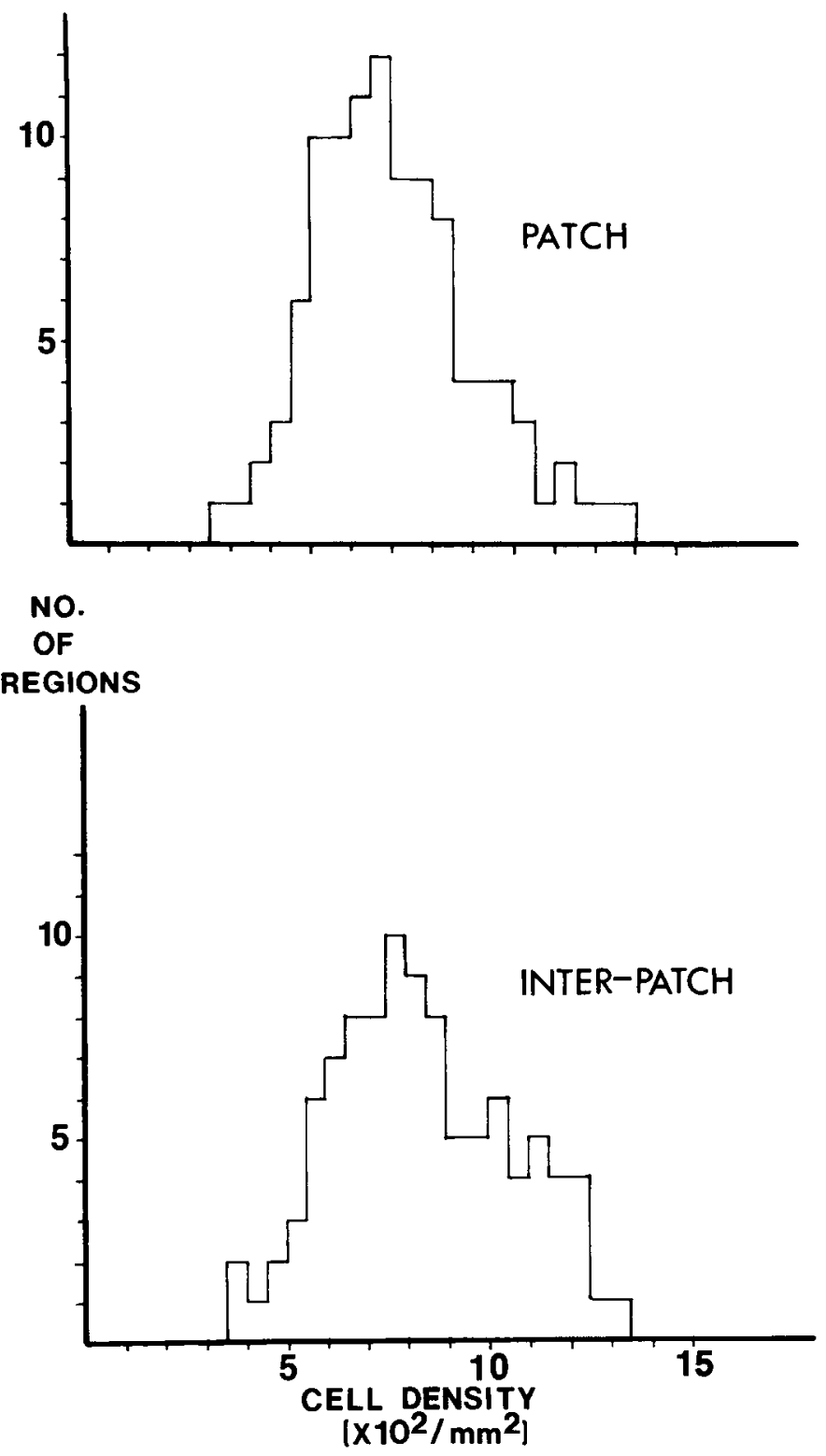

Figure 10. Graphs showing the relationship of GABA-immunoreactive cell density and the presence of $\mathrm{CO}$-stained patches in sections through the superficial layers of area 17. Both the CO patches and the interpatch spaces contain a wide range of GABA cell densities that form normal distributions for each region.

with strong chemical fixatives ( $2.5 \%$ glutaraldehyde) also suggests that loss of staining with fixation is not a significant problem. Third, failure to detect GABA may arise from the difficulties in fixing the molecule in place, since even $5 \%$ glutaraldehyde fixes only half the available GABA molecules (Taxt and Storm-Mathisen, 1979). Previous investigators have used relatively high concentrations of glutaraldehyde to localize GABA immunocytochemically (Ottersen and Storm-Mathisen, 1984), but we found that increasing concentrations of this aldehyde did not increase the numbers and densities of GABApositive neurons in our material and that high concentrations produced uneven staining of the cortex. We conclude that for both numbers and evenness of staining, the methods we have used are optimal, but we recognize that improvements in methods might significantly increase the numbers of cells identified as GABA neurons.
Recent evidence suggests that neurotransmitter levels can be regulated by neuronal activity (Black et al., 1984). Of particular significance to the present study are the findings that changes in the immunocytochemical staining for GABA, and thus reductions in the numbers of GABA-positive neurons, can be produced in area 17 of monkeys by visual deprivation (Hendry and Jones, 1986). Similar changes may be a feature of normal cortical physiology, so that a population of GABA neurons from time to time may not contain enough GABA to be detected by immunocytochemistry. Again, such a circumstance could have led us to count too few neurons as GABA immunoreactive. Therefore, our results can be viewed as representing the minimum number of cells that are immunocytochemically stained for GABA in the monkey cerebral cortex.

We cannot state categorically that all cortical cells stained for GABA are neurons that contain the amino acid and use it as a neurotransmitter. First, neuroglial cells actively take up GABA (Schon and Kelly, 1974a; Iversen and Kelly, 1975; Kelly and Dick, 1975) and might have been stained. However, we have seen no GABA-immunoreactive neuroglial cells in preliminary ultrastructural studies of this same material (S. H. C. Hendry, J. DeFelipe, and E. G. Jones, unpublished observations). Perhaps the different modes of GABA metabolism in neurons and glia (Schon and Kelly, 1974b) account for the apparent failure of our methods to detect GABA in neuroglial cells. A second potential source of false-positive staining may arise if the antiserum used in this study cross-reacts with a molecule similar to GABA in at least some neurons. Adsorption controls in which several likely candidates (including putative neurotransmitters glutamate, glycine, aspartate, and taurine) were checked for crossreactivity revealed no evidence that the antiserum was detecting these molecules, but to identify and check every potential crossreacting substance was not possible. Although our results agree with numerous previous studies (see introduction) implicating GABA as a neurotransmitter in neurons of the cerebral cortex, the possibility still remains that some immunoreactive cells contain not GABA, but a GABA-like substance. This would seem to be the main potential source for any overestimation of GABA cell numbers in our material.

\section{Quantitative studies of the cerebral cortex}

Proportion of GABA neurons

In comparison with the present study, most previous studies have estimated that fewer cells in the mammalian cerebral cortex are GABA neurons. Less than $10 \%$ of the neurons in areas of the monkey cortex are immunoreactive for GAD (Fitzpatrick et al., 1983; Houser et al., 1983). A recent study of cat area 17 (Gabbott and Somogyi, 1986) and the present study of 10 areas of monkey cortex contrast with the previous results in detecting at least twice that proportion of GABA neurons. Gabbott and Somogyi (1986) calculated that $20 \%$ of the neurons in cat area 17 are GABA positive, and we have found that $20 \%$ of the neurons in monkey area 17 and possibly area $3 \mathrm{~b}$ and $25 \%$ in the remaining areas are GABA immunoreactive. Differences between the earlier studies and the more recent ones may be due to the use of different antisera and the use of methods that optimize antibody penetration. The lower estimates come from studies of GAD immunoreactivity, which is frequently difficult to detect in somata without the use of colchicine to inhibit axoplasmic transport (Ribak et al., 1978; Houser et al., 1984), while the higher estimates of the present study and that of Gabbott and Somogyi (1986) are of cells stained for GABA itself. 
It appears that in both cat and monkey cortex, 1 out every 5 and, in many areas, 1 out of every 4 neurons is immunoreactive for GABA. The data suggest that a large proportion of cortical neurons in these animals may use GABA as a neurotransmitter, and the numbers are presumably a reflection of the proportion of inhibitory interneurons in the cortex.

\section{Cortical homogeneity}

Previous studies of the neuronal population in the mammalian ccrebral cortcx have reported a uniform density of ncurons across areas and species, except for area 17 of primates (Rockel et al., 1980). These data have been interpreted as showing that the cerebral cortex is a basically homogeneous structure that varies little in its neuronal composition among areas and species (Powell, 1981). The present data on the numbers, densities, and proportions of GABA neurons also indicate a basic similarity among most areas of monkey cortex. The same numbers and proportions of GABA neurons are found in 50- $\mu \mathrm{m}$-wide columns through the thickness of areas $4,1-2,5,7$, and 18, as well as in areas of temporal and prefrontal cortex. Area 17, which has more than twice the number of neurons and 1.5 times the number of GABA neurons per column, and area $3 \mathrm{~b}$, which had significantly fewer GABA neurons per $50 \mu \mathrm{m}$ column in 3 monkeys but not in 2 others, differ from the others. We cannot account for the different values for area $3 \mathrm{~b}$ in the 5 animals, but since our methods may fail to detect some proportion of $\mathrm{G} \Lambda \mathrm{B} \Lambda$ neurons in each animal (see above), we are inclined to see the larger number as more closely representing the usual size of the GABA population in this area. If so, then all areas but 17 , which is recognized as unique among areas of the monkey cortex in its neuronal composition (Rockel et al., 1980), would appear to contain the same number of GABA neurons.

Does the presence of the same number of GABA neurons within columns through several cortical areas indicate that these areas possess similar neuronal circuitry? This question of whether the mammalian cortex is a homogeneous structure for which a basic, repeating circuit can be described must take into account the varieties of neurons within every column. The GABA neurons, themselves, are a markedly heterogenous population, composed of several morphologically (Houser et al., 1984) and neurochemically (Hendry et al., 1984a; Schmechel et al., 1984; Somogyi et al., 1984) distinct classes; they make up only part of the population of cortical nonpyramidal cells (Jones, 1981) and form parts of circuits that include a large group of morphologically and connectionally distinct pyramidal neurons (Gilbert and Kelly, 1975; Lund et al., 1975; Jones and Wise, 1977; Gilbert and Wiesel, 1979; Martin and Whitteridge, 1984). Quantitative studies, including ones directed at a well-defined subpopulation of neurons, cannot determine whether each of the neuronal types is equally represented across areas and occupies the same position within neural circuits of one area as it does in those of others. The density and laminar distribution of at least some markers for cortical intrinsic neurons (e.g., somatostatin and neuropeptide $\mathrm{Y}$ ) and afferent axons vary greatly across areas of monkey cortex (Hendry et al., 1984a; Lewis et al., 1987). Thus, while broad, quantitative similarities exist across areas of monkey cerebral cortex with regard to some parameters, there remain many features of neuronal organization that appear to differ or that have not been examined.

The laminar distribution of GABA neurons varies among areas of monkey cortex, with the densest collections of immunoreactive cells being correlated with the positions of the main concentrations of thalamocortical axon terminations. Within the cytoarchitectonic fields of the first somatosensory area, thalamocortical axons terminate principally in layers IIIB and IV of area $3 \mathrm{~b}$ and layer IIIB of areas 1-2 (Jones, 1975; Jones and Burton, 1976). High densities of GABA neurons follow that pattern. In areas 5 and 7, where the main thalamocortical axon terminations also occupy layer IIIB (Jones, 1975; Jones and Burton, 1976), the GABA neurons are densely packed in that layer. Both GABA neurons and thalamic afferent terminations (Curcio and Harting, 1978; Livingstone and Hubcl, 1982) are dense in layers III and IV of area 18, while in area 17 the findings of the present study and those of previous studies of GAD localization (Hendrickson et al., 1981) show a clear correlation between thalamic axon terminations and GABA neurons, with both being very dense in layers IVA and IVC. Thus, the differences we have seen in the distribution of GABA neurons among areas of monkey cortex reflect differences in the positions of the main thalamic afferent plexuses and presumably of major populations of neurons on which the afferent axons terminate.

Previous studies of the neuronal composition of layer IV have indicated that from 5 to $50 \%$ of its neurons may be GABA cells. In area 17 of monkeys, $95 \%$ of the neurons in layer IVC reportedly have ultrastructural features that are suggested to be indicative of spiny nonpyramidal cells (Mates and Lund, 1983) and, thus, of non-GABA neurons (Jones, 1981), leaving only $5 \%$ that might be $\mathrm{G} \Lambda \mathrm{B} \Lambda$ ergic. By contrast, studies of neurons labeled by the uptake of ${ }^{3} \mathrm{H}-\mathrm{GABA}$ in area $3 \mathrm{~b}$ suggested that a far larger population, approaching half the number of layer IV neurons, may be GABA cells (Hendry and Jones, 1981). The findings of the present study, based on a more reliable marker for GABA neurons, indicate that a significant population of layer IV neurons, certainly greater than $5 \%$, is GABA immunoreactive in most areas of monkey cortex, including layer IVC of area 17. However, in no area, including area $3 \mathrm{~b}$, did GABA-positive neurons come close to forming half the neuronal population. The present findings are more in accord with those reported previously for GAD- and GABA-positive neurons in area 17 of monkeys (Fitzpatrick et al., 1983) and cats (Gabbott and Somogyi, 1986)

We found a larger number of neurons within columns of $50 \times$ $15 \mu \mathrm{m}$ (width $\times$ thickness) than has been reported for columns of $30 \times 25 \mu \mathrm{m}$ (Rockel et al., 1980). The difference is most likely due to the greater shrinkage of the tissue examined in the present study, which is inherent to the immunocytochemical procedure, particularly when detergents are used. Even though many counts were made from sections that had been stained with thionin only, we processed this tissue in the same reagents (normal sera and detergent) as the immunocytochemically stained sections so that the shrinkage in the 2 sets of sections would be equal. From the plastic semithin sections examined in this study we have made preliminary calculations of the total number of neurons per cubic millimeter in area 17; the values we found varied from 118,300 to $120,400 / \mathrm{mm}^{3}$. These values are very close to those calculated previously for monkey area 17 (O'Kusky and Colonnier, 1982), indicating that once tissue shrinkage is taken into consideration, our findings and those of previous investigators are in close agreement.

\section{Intra-areal differences in $G A B A$ neuron density}

We found that the numbers of GABA neurons in $50-\mu \mathrm{m}$-wide columns vary within individual areas of monkey cortex. The variations are greatest in area $3 b$ of the parietal lobe and in 
areas 17 and 18 of the occipital lobe. It is uncertain whether the intra-areal differences in GABA cell numbers reflect biological variabilities or technical ones, since histological preparation of tissue can affect the numbers of GABA neurons stained for GABA, as seen in the thick frozen sections or Vibratome sections processed in this study. Similarly, the use of high (2.5\%) glutaraldehyde concentrations or the omission of detergents from the staining procedure produces uneven distributions of GABApositive neurons, in which the maximum number of cells per $50 \mu \mathrm{m}$ column does not differ from more homogeneously stained sections but in which steep declines are seen in the minimum number of cells per column. We interpret these variations in less than optimally prepared material as having a common mechanism, namely, the uneven penetration of immunocytochemical reagents into the sections.

There are 2 reasons for assuming that the intra-areal variations in GABA cell numbers seen in the present study are not artifactual. (1) These variations occur because of changes in GABA cell numbers in only 1 or 2 layers, while the number of GABA cells per column does not vary significantly in the remaining layers. (2) The layers displaying changes in GABA cell numbers differ from one area to the next (layer IV of area $3 b$, layers II and III of area 17, and layers III and V in area 18). These data suggest that the number of GABA cells found within an area varied not because of methodological problems, but because of variations within the area itself.

In areas 17 and 18 of the monkey cortex and in the first somatosensory arca of rodents, intrinsic organizational patterns exist that can be detected histochemically (Killackey and Belford, 1979; Horton and Hubel, 1981; Livingstone and Hubel, 1982). Neurons in layer IV of rat somatosensory are organized into dense cellular aggregates (barrels), the sides of which are densely packed with GAD-positive neurons (Lin et al., 1985). We examined area 17 in the present study to determine if its organization into rows of CO-stained periodicities (Horton and Hubel, 1981) is also reflected in the distribution of GABA neurons. It is known that GAD-positive terminals are densest within the CO-stained patched of layers II and III (Hendrickson et al., 1981), and there are data to suggest that neurons accumulating ${ }^{3} \mathrm{H}-\mathrm{GABA}$ are concentrated within the patches (Carroll and Wong-Riley, 1985). However, the results of the present study and those of previous studies (Fitzpatrick et al., 1983) indicate that GABA- and GAD-immunoreactive cell bodies are no denser in the patches than they arc outside them. Both high and low densities of GABA neurons are found in patches and outside them, showing that, as predicted from our autocorrelation statistics, no clearly defined periodicity exists in GABA cell distribution within the supragranular layers of monkey area 17. Further study will be necessary to determine if the variabilities in the number of GABA neurons correspond to some other aspect of area 17 .organization.

We examined a limited number of $50 \mu \mathrm{m}$ columns in area 18 (to a total width of $2 \mathrm{~mm}$ ) and found no clear evidence of a regular pattern to the distribution of GABA neurons. However, staining for $\mathrm{CO}$ in area 18 reveals a series of thick (1-mmwide) and thin (200- $\mu \mathrm{m}$-wide) stained bands that alternate with thin $(200-\mu \mathrm{m}$-wide) unstained bands (Livingstone and Hubel, 1982). Clearly, more than $2 \mathrm{~mm}$ would have to be examined to detect a periodicity that matched the pattern of CO staining. By inspection, it appears that the peaks in $\mathrm{G} \Lambda \mathrm{B} \Lambda$ cell density vary from wide $(600-700 \mu \mathrm{m})$ to narrow $(200-300 \mu \mathrm{m})$, while the regions of low density are also narrow. In addition, the variations in GABA cell density are found in layers III and V, where $\mathrm{CO}$ staining also varies. These data suggest that some correlation may exist between the distribution of GABA cells in monkey area 18 and the periodic staining for $\mathrm{CO}$ in that arca.

\section{References}

Black, I. B., J. E. Adler, C. F. Dreyfus, G. M. Jonakait, D. M. Katz, E. F. LaGamma, and K. M. Markey (1984) Neurotransmitter plasticity at the molecular level. Science 225: 1266-1270.

Carroll, E. W., and M. Wong-Riley (1985) Correlation between cytochrome oxidasc staining and the uptake and laminar distribution of triated aspartate, glutamate, $\gamma$-aminobutyrate and glycine in the striate cortex of the squirrel monkey. Neuroscience 15: 959-976.

Celio, M. R. (1986) Parvalbumin in most $\gamma$-aminobutyric acid-containing neurons of the rat cerebral cortex. Science 231: 995-997.

Curcio, C. A., and J. K. Harting (1978) Organization of pulvinar afferents to area 18 in the squirrel monkey: Evidence for stripes. Brain Res. 143: 155-161.

DeFelipe, J., S. H. C. Hendry, and E. G. Jones (1986) A correlative electron microscopic study of basket cells and large GABAergic neurons in the monkey sensory-motor cortex. Neuroscience 17: 9911009.

Dykes, R. W., P. Landry, R. Metherate, and T. P. Hicks (1984) Functional role of GABA in cat primary somatosensory cortex: Shaping receptive ficlds of cortical neurons. J. Neurophysiol. 52: 1066-1093.

Fitzpatrick, D., J. S. Lund, and D. Schmechel (1983) Glutamic acid decarboxylase immunoreactive neurons and terminals in the visual cortex of monkey and cat. Soc. Neurosci. Abstr. 9: 616.

Freund, T. F., K. A. C. Martin, A. D. Smith, and P. Somogyi (1983) Glutamate decarboxylase-immunoreactive terminals of Golgi-impregnated axoaxonic cells and of presumed basket cells in synaptic contact with pyramidal neurons of the cat's visual cortex. J. Comp. Neurol. 221: 263-278.

Gabbott, P. L. A., and P. Somogyi (1986) Quantitative distribution of GABA-immunoreactive neurons in the visual cortex (area 17) of the cat. Exp. Brain Res. 61: 323-331.

Gilbert, C. D., and J. P. Kelly (1975) The projections of cells in different layers of the cat's visual cortex. J. Comp. Neurol. 163: 81106.

Gilbert, C. D., and T. N. Wiesel (1979) Morphology and intracortical projections of functionally characterized neurones in the cat visual cortex. Nature 280: 120-125.

Graybiel, A. M., and C. W. Ragsdale (1982) Pseudocholinesterase staining in the primary visual pathway of the macaque monkey. Nature 299: 439-442.

Harnett, D. L. (1982) Statistical Methods, 3rd. ed., Addison-Wesley, Reading, MA.

Hendrickson, A. E., S. P. Hunt, and J.-Y. Wu (1981) Immunocytochemical localization of glutamic acid decarboxylase in monkey striate cortex. Nature 292: 605-607.

Hendry, S. H. C., and E. G. Jones (1981) Sizes and distributions of intrinsic neurons incorporating tritiated GABA in monkey sensorymotor cortcx. J. Ncurosci. 1: 390-408.

Hendry, S. H. C., and E. G. Jones (1986) Reduction in number of immunostained GABAergic neurones in deprived-eye dominance columns of monkey area 17. Nature 320: 750-753.

Hendry, S. H. C., E. G. Jones, J. DeFelipe, D. Schmechel, C. Brandon, and P. C. Emson (1984a) Neuropeptide-containing neurons of the cerebral cortex are also GABAergic. Proc. Natl. Acad. Sci. USA. 81: 6526-6530.

Hendry, S. H. C., E. G. Jones, and P. C. Emson (1984b) Morpholology, distribution and synaptic relations of somatostatin- and neuropeptide $\mathrm{Y}$-immunoreactive neurons in rat and monkey neocortex. J. Neurosci. 4: 2497-2517.

Hicks, T. P., and R. W. Dykes (1983) Receptive field size for certain neurons in primary somatosensory cortex is determined by GABAmediated intracortical inhibition. Brain Res. 274: 160-164.

Hirsch, H., and E. Robins (1962) Distribution of $\gamma$-aminobutyric acid in the layers of the cerebral and cerebellar cortex. Implications for its physiological role. J. Neurochem. 9: 63-70.

Horton, J., and D. H. Hubel (1981) Regular patchy distribution of 
cytochrome oxidase staining in primary visual cortex of macaque monkey. Nature 292: 762-764.

Houser, C. R., S. H. C. Hendry, E. G. Jones, and J. E. Vaughn (1983) Morphological diversity of immunocytochemically identified GABA neurons in the monkey sensory-motor cortex. J. Neurocytol. 12:617638 .

Houser, C. R., J. E. Vaughn, S. H. C. Hendry, E. G. Jones, and A. Peters (1984) GABA neurons in the cerebral cortex. In Cerebral Cortex, E. G. Jones and A. Peters, eds., pp. 63-89, Plenum, New York.

Iversen, L. L., and J. S. Kelly (1975) Uptake and metabolism of $\gamma$-aminobutyric acid by neurones and glial cells. Biochem. Pharmacol. 24: 933-938.

Iversen, L. L., J. F. Mitchell, and V. Srinivasan (1971) The release of gamma-aminobutyric acid during inhibition in the cat visual cortex. J. Physiol. (Lond.) 212: 519-534.

Jones, E. G. (1975) Lamination and differential distribution of thalamic afferents within the sensory-motor cortex of the squirrel monkey. J. Comp. Neurol 160: 167-203.

Jones, E. G. (1981) Anatomy of cerebral cortex: Columnar inputoutput organization. In The Cerebral Cortex, F. O. Schmitt, F. G. Worden, G. Adelman, and M. Dennis, eds., pp. 199-235, MIT Press, Cambridge, MA.

Jones, E. G., and H. Burton (1976) Areal differences in the distribution of thalamocortical fibers in cortical fields of the insular, parietal and temporal regions of primates. J. Comp. Neurol. 168: 197-248.

Jones, E. G., and S. P. Wise (1977) Size, laminar and columnar distribution of efferent cells in the sensory-motor cortex of monkeys. J. Comp. Neurol. 178: 391-437.

Kelly, J. S., and F. Dick (1975) Differential labeling of glial cells and GABA-inhibitory interneurons and nerve terminals following the microinjection of $\left[\mathrm{B}^{-}{ }^{3} \mathrm{H}\right]$ alanine, $\left[{ }^{3} \mathrm{H}\right] \mathrm{DABA}$ and $\left[{ }^{3} \mathrm{H}\right] \mathrm{GABA}$ into single folia of the cerebellum. Cold Spring Harbor Symp. Quant. Biol. 40: 93-106.

Killackey, H. P., and G. R. Belford (1979) The formation of afferent patterns in the somatosensory cortex of the neonatal rat. J. Comp. Neurol. 183: 285-304.

Krnjević, K. (1974) Chemical nature of synaptic transmission in vertebrates. Physiol. Rev. 54: 318-450.

Krnjević, K. (1984) Neurotransmitters in cerebral cortex: A general account. In Cerebral Cortex, E. G. Jones and A. Peters, eds., pp. 3961, Plenum, New York

Krnjević, K., and S. Schwartz (1967) The action of $\gamma$-aminobutyric acid on cortical neurones. Exp. Brain Res. 3: 320-326.

LaVail, J. H., and M. M. LaVail (1974) The retrograde intra-axonal transport of horseradish peroxidase in the chick visual system: A light and electron microscopic study. J. Comp. Neurol. 157: 303-357.

Lewis, D. A., M. J. Campbell, S. L. Foote, M. Goldstein, and J. H. Morrison (1987) The distribution of tyrosine hydroxylase-immunoreactive fibers in primate neocortex is widespread but regionally specific. J. Neurosci. 7: 279-290.

Lin, C.-S., S. M. Liu, and D. E. Schmechel (1985) Glutamic acid decarboxylase immunoreactivity in layer IV of barrel cortex of rat and mouse. J. Neurosci. 5: 1934-1939.

Livingstone, M. S., and D. H. Hubel (1982) Thalamic inputs to cytochrome oxidase-rich regions in monkey visual cortex. Proc. Natl. Acad. Sci. USA 79: 6098-6101.

Lund, J. S., R. D. Lund, A. E. Hendrickson, A. H. Bunt, and A. F. Fuchs (1975) The origin of efferent pathways from the primary visual cortex, area 17, of the macaque monkey as shown by the retrograde transport of horseradish peroxidase. J. Comp. Neurol. 164: 287-303.

Martin, K. A. C., and D. Whitteridge (1984) Form, function and intracortical projections of spiny neurones in the striate visual cortex of the cat. J. Physiol. (Lond.) 353: 463-504.
Mates, S. L., and J. S. Lund (1983) Neuronal composition and development in lamina $4 \mathrm{C}$ of monkey striate cortex. J. Comp. Neurol. 221: 60-90.

O'Kusky, J., and M. Colonnier (1982) A laminar analysis of the number of neurons, glia, and synapses in the visual cortex (area 17) of adult macaquc monkcys. J. Comp. Neurol. 210: 278-290.

Ottersen, O. P., and J. Storm-Mathisen (1984) Glutamate- and GABAcontaining neurons in the mouse and rat brain as demonstrated with a new immunocytochemical technique. J. Comp. Neurol. 229: 374392.

Peters, A., and D. A. Kara. (1985) The neuronal composition of area 17 of rat visual cortex. II. The non-pyramidal cells. J. Comp. Neurol. 234: 242-263.

Powell, T. P. S. (1981) Certain aspects of the intrinsic organisation of the cerebral cortex. In Basic Mechanisms and Perceptual Awareness, O. Pompeiano and C. Ajmone Marsan, eds., pp. 1-19, Raven, New York.

Ribak, C. E., J. E. Vaughn, and K. Saito (1978) Immunocytochemical localization of glutamic acid decarboxylase in neuronal somata following colchicine inhibition of axonal transport. Brain Res. 140: 315 332.

Ribak, C. E., A. B. Harris, J. E. Vaughn, and E. Roberts (1979) Inhibitory, GABAergic nerve terminals decrease at sites of focal epilepsy. Science 205: 211-214.

Ribak, C. E., C. A. Hunt, R. E. Bakay, and W. H. Oertel (1986) A decrease in the number of GABAergic somata associated with the preferential loss of GABAergic terminals at epileptic foci. Brain Res. 363: 78-90.

Richardson, K. D., L. Jarett, and E. H. Fink (1960) Embedding in epoxy resins for ultrathin sectioning in electron microscopy. Stain Technol. 35: 313-323.

Rockel, A. J., R. W. Hiorns, and T. P. S. Powell (1980) The basic uniformity in structure of the neocortex. Brain 103: 221-244.

Schmechcl, D. G., B. G. Vickrcy, D. Fitzpatrick, and R. P. Elde (1984) GABAergic neurons of mammalian cerebral cortex: Widespread subclass defined by somatostatin content. Neurosci. Lett. 47: 227-232.

Schon, F., and J. S. Kelly (1974a) Autoradiographic localisation of $\left[{ }^{3} \mathrm{H}\right] \mathrm{GABA}$ and $\left[{ }^{3} \mathrm{H}\right]$ glutamate over satellite glial cells. Brain Res. 66 . 275-288.

Schon, F., and J. S. Kelly (1974b) The characterization of [3]GABA uptake into the satellite glial cells of rat sensory ganglia. Brain Res. 66: 289-300.

Sillito, A. M. (1984) Functional considerations of the operation of GABAergic inhibitory processes in the visual cortex. In Cerebral Cortex, E. G. Jones and A. Peters, eds., pp. 91-117, Plenum, New York.

Somogyi, P., A. J. Hodgson, A. D. Smith, M. G. Nunzi, A. Gorio, and J.-Y. Wu (1984) Different populations of GABAergic neurons in the visual cortcx and hippocampus of cat contain somatostatin- or cholecystokinin-immunoreactive material. J. Neurosci. 4: 2590-2603.

Taxt, T., and J. Storm-Mathisen (1979) Tentative localization of glutamergic and aspartergic nerve endings in brain. J. Physiol. (Paris) 75: $667-684$.

Weibel, E. R. (1969) Stereological principles for morphometry in electron microscopic cytology. In International Reviews of Cytology, $\mathrm{G}$ H. Bourne and J. F. Danelli, eds., pp. 235-302, Academic, New York.

Weibel, E. R., and P. Bolender (1973) Stereological techniques for electron microscopic morphometry. In Principles and Techniques of Electron Microscopy, M. A. Hyat, ed., pp. 237-296, Van Nostrand Reinhold, New York.

Wise, S. P., and M. Herkenham (1982) Opiate receptor distribution in the cerebral cortex of the rhesus monkey. Science 218: 387-389.

Wong-Riley, M. T. T. (1979) Changes in the visual system of monocularly sutured or enucleated cats demonstrable with cytochrome oxidase histochemistry. Brain Res. 171: 11-28. 